\title{
A Pacific Centennial Oscillation Predicted by Coupled GCMs*
}

\author{
KRISTOPHER B. KARNAUSKAS \\ Woods Hole Oceanographic Institution, Woods Hole, Massachusetts \\ JASON E. SMERDON AND RichARD SEAGER \\ Lamont-Doherty Earth Observatory, Columbia University, Palisades, New York \\ JESÚS FIDEL GONZÁLEZ-ROUCO \\ Universidad Complutense de Madrid, Madrid, Spain
}

(Manuscript received 28 July 2011, in final form 30 March 2012)

\begin{abstract}
Internal climate variability at the centennial time scale is investigated using long control integrations from three state-of-the-art global coupled general circulation models. In the absence of external forcing, all three models produce centennial variability in the mean zonal sea surface temperature (SST) and sea level pressure (SLP) gradients in the equatorial Pacific with counterparts in the extratropics. The centennial pattern in the tropical Pacific is dissimilar to that of the interannual El Niño-Southern Oscillation (ENSO), in that the most prominent expression in temperature is found beneath the surface of the western Pacific warm pool. Some global repercussions nevertheless are analogous, such as a hemispherically symmetric atmospheric wave pattern of alternating highs and lows. Centennial variability in western equatorial Pacific SST is a result of the strong asymmetry of interannual ocean heat content anomalies, while the eastern equatorial Pacific exhibits a lagged, Bjerknes-like response to temperature and convection in the west. The extratropical counterpart is shown to be a flux-driven response to the hemispherically symmetric circulation anomalies emanating from the tropical Pacific.

Significant centennial-length trends in the zonal SST and SLP gradients rivaling those estimated from observations and model simulations forced with increasing $\mathrm{CO}_{2}$ appear to be inherent features of the internal climate dynamics simulated by all three models. Unforced variability and trends on the centennial time scale therefore need to be addressed in estimated uncertainties, beyond more traditional signal-to-noise estimates that do not account for natural variability on the centennial time scale.
\end{abstract}

\section{Introduction}

The dominant influence of the tropical Pacific on global interannual climate variability has motivated considerable interest in understanding its potential response to anthropogenic forcing, including whether the tropical Pacific could become more El Niño- or La Niña-like in the future. Much depends on the answer; for example,

* Lamont-Doherty Earth Observatory Contribution Number 7550.

Corresponding author address: Kristopher B. Karnauskas, Woods Hole Oceanographic Institution, 360 Woods Hole Road, MS \#23, Woods Hole, MA 02544.

E-mail: kk@whoi.edu the amount of future drying in southwestern North America and even the sign of hydrologic change in large parts of South America appear to depend on whether the zonal sea surface temperature (SST) gradient in the equatorial Pacific strengthens or weakens (Seager and Vecchi 2010). Additionally, past hydrological events, such as major North American droughts (Schubert et al. 2004; Seager et al. 2005b) and the global precipitation trend over recent decades (Hoerling et al. 2010; Seager and Vecchi 2010; Seager and Naik 2012), have been strongly influenced by changes in the equatorial Pacific zonal SST gradient that amount to no more than a fraction of a degree centigrade. Although the actual response of the tropical Pacific to radiative forcing (of any origin) is not yet clear, paleoclimate records indicate that significant changes in the equatorial zonal 
SST gradient may have occurred over thousands to millions of years (e.g., Wara et al. 2005). Recent modeling work has also suggested that the zonal SST gradient in the Indo-Pacific sector may have played an important role in shaping the atmospheric circulation and hydrological regime during the Medieval Climate Anomaly at the turn of the last millennium (Burgman et al. 2010; Graham et al. 2010). It therefore is likely that changes in the gradient will play an important role in shaping the character of contemporary climate change, which further underscores the importance of understanding the magnitude of variability in the equatorial SST gradient and the underlying dynamics on a wide range of time scales.

A growing number of studies have used instrumental data to quantify observed changes in the mean climate of the tropical Pacific, including any potential response to anthropogenic forcing (Cane et al. 1997; Cane 2005; Vecchi et al. 2008; Karnauskas et al. 2009; Bunge and Clarke 2009; Compo and Sardeshmukh 2010; Kumar et al. 2010; Deser et al. 2010; Tung and Zhou 2010; Zhang et al. 2010). These studies adopt various approaches for addressing the signal-to-noise problem of estimating long-term trends in 100-150-yr time series that contain high-amplitude variance at interannual and longer time scales. Nevertheless, they do not consider the possibility that unforced centennial variability inherent to the coupled dynamics of the tropical Pacific could also create century-length trends.

Characterizing unforced, internal variability at the centennial time scale is critical for detecting and attributing externally forced changes due to anthropogenic emissions of greenhouse gases. The era of modern instrumental records of key climate variables such as SST and sea level pressure (SLP) began less than 200 years ago, requiring that this variability be characterized with paleoclimatic evidence or multicentury simulations from general circulation models (GCMs). Until very recently, only simple models or models of intermediate complexity limited in domain to the tropical Pacific basin (e.g., Zebiak and Cane 1987) could be integrated over sufficiently long periods to quantify internal lowfrequency variability. Control and forced simulations from fully coupled GCMs that span a millennium or more are, however, becoming more widely available (e.g., González-Rouco et al. 2003, 2006, 2011; Ammann et al. 2007; Wittenberg 2009). Such simulations enable the robust characterization of multidecadal-to-centennial variability in model-simulated climates. Wittenberg (2009) showed that the range of internal low-frequency variability in the period and amplitude of the El NiñoSouthern Oscillation (ENSO) in a 2000-yr GCM control simulation precludes the attribution of changes in
ENSO behavior seen in the modern instrumental record to anthropogenic or external forcing. Yeh et al. (2011) used a similarly complex model to quantify lowfrequency variations in the spatial pattern of ENSO, contrasting the eastern and central Pacific flavors of El Niño events. Corroborating these coupled model studies, McGregor et al. (2010) and Li et al. (2011) have recently presented proxy evidence from tree rings, tropical corals, and other sources for significant variability in the amplitude of ENSO on interdecadal time scales.

Focusing on characterizing and understanding the unforced, internal variability in the mean state of the tropical and extratropical Pacific Ocean, we examine centennial climate variability in global output fields from long control integrations of three state-of-the-art global coupled GCMs. The models and supporting observational datasets are briefly described in the following section, section 3 presents the patterns of unforced climate variability with a proposed mechanism, and the implications for forced-trend detection are discussed in section 4. A summary and discussion are given in section 5 .

\section{Models}

Annual resolution output fields from millennial control integrations of three fully coupled global GCMs are employed in this study. In the simulations, solar radiation, atmospheric composition, and all other aspects of the external forcing are held constant. Simulated climate variability at any time scale is therefore solely the result of internal dynamics captured by the model rather than a response to any specified forcing.

The Geophysical Fluid Dynamics Laboratory Climate Model version 2.1 (GFDL CM2.1) is described by Delworth et al. (2006). The control simulation analyzed herein was run with an atmospheric resolution of $2^{\circ}$ latitude $\times 2^{\circ}$ longitude $\times 24$ vertical levels; oceanic resolution is $1^{\circ}$ latitude (increasing to $1 / 3^{\circ}$ near the equator $) \times 1^{\circ}$ longitude $\times 50$ levels. The simulation spans 3000 years after omitting the first 700 years as model spinup. Simulation of the tropical Pacific climate and ENSO variability by the GFDL model is assessed by Wittenberg et al. (2006); despite biases in mean climate common to most coupled models, such as an equatorial cold bias, the basic climatology as well as the spatial pattern and periodicity of ENSO are well reproduced. The GFDL model does not apply flux adjustment.

The National Center for Atmospheric Research (NCAR) Community Climate System Model, version 4 (CCSM4), part of the latest Community Earth System Model, version 1, is described by Gent et al. (2011). The 
EOF 1

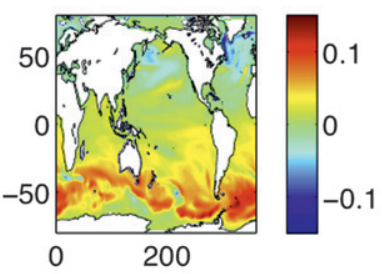

EOF 3
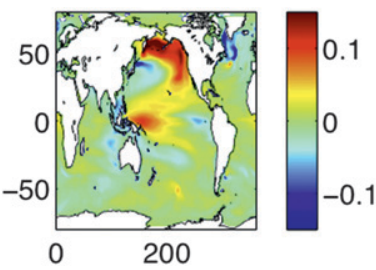

EOF 2

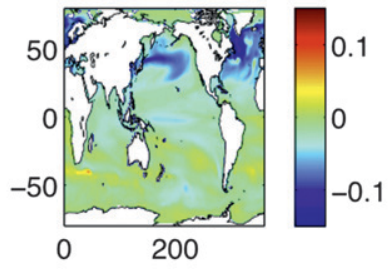

EOF 4

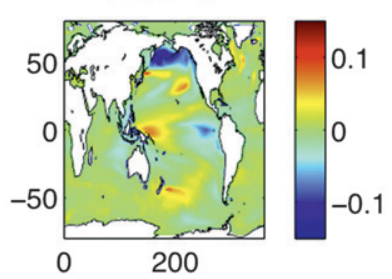

PC 1

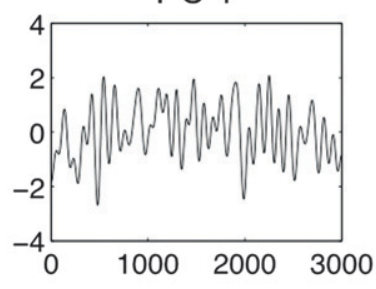

PC 3

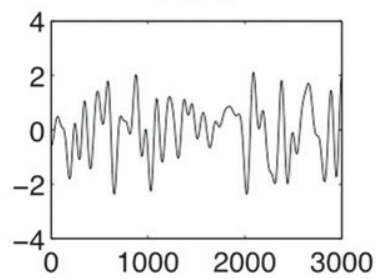

PC 2
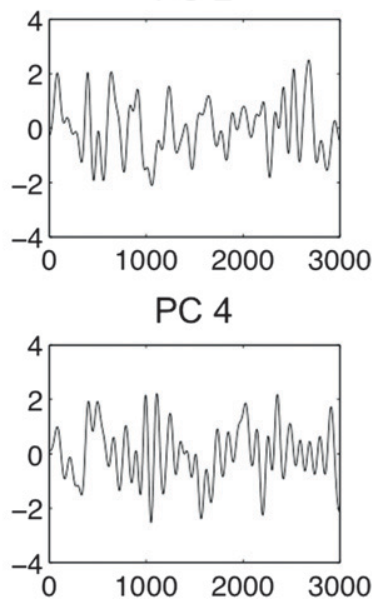

FIG. 1. (left) The leading four EOFs and (right) associated PCs of filtered (90-yr low pass) SST from the GFDL CM2.1. EOFs are expressed in ${ }^{\circ} \mathrm{C}$ per standard deviation, and PCs are expressed in standard deviations. Variances explained are $20.5 \%, 16.5 \%, 14.7 \%$, and $7.0 \%$ for EOF1, EOF2, EOF3, and EOF4, respectively. In the right panels, the $x$ axis is time in years.

control simulation used herein spans 1300 years and employs the version of CCSM4 with an atmospheric resolution of $\sim 1^{\circ}$ latitude $\times 1^{\circ}$ longitude $\times 26$ vertical layers and an oceanic resolution of $1.11^{\circ}$ longitude $\times$ $0.54^{\circ}$ latitude (increasing to $0.27^{\circ}$ near the equator) $\times 60$ vertical levels. This version of CCSM4 includes improvements to the parameterization of deep convection (Neale et al. 2008; Richter and Rasch 2008) that led to significant improvements in simulation of ENSO over the previous CCSM versions. The NCAR CCSM4 also does not apply flux adjustment.

The ECHO-G coupled climate model (Legutke and Voss 1999) combines the ECHAM4 atmospheric model (Roeckner et al. 1996) with the global version of the
Hamburg Ocean Primitive Equation (HOPE-G) ocean model (Legutke and Maier-Reimer 1999). The control simulation used herein was run at T30 $\left(\sim 3.75^{\circ}\right) \times 19$ levels atmospheric resolution, T42 $\left(\sim 2.8^{\circ}\right.$; meridional resolution increasing to $\sim 0.5^{\circ}$ near the equator $) \times 20$ levels oceanic resolution, and spans 1000 years. The ECHO-G model applies a time-invariant flux adjustment (heat and freshwater fluxes) to avoid climate drift. An assessment of the simulated mean climate and ENSO variability by the ECHO-G model is given by Min et al. (2005).

To compare forced and unforced climate variability, we also analyze output fields from transient simulations of the twentieth and twenty-first centuries by each of
EOF 1

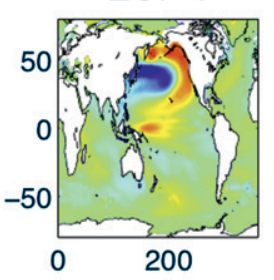

EOF 3

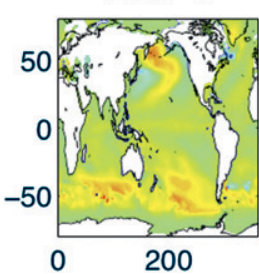

EOF 2

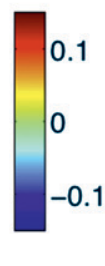

1

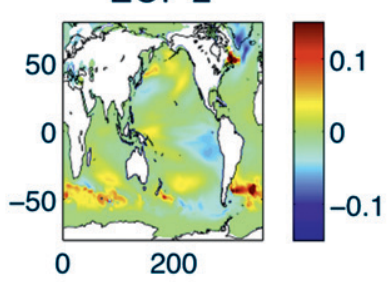

EOF 4
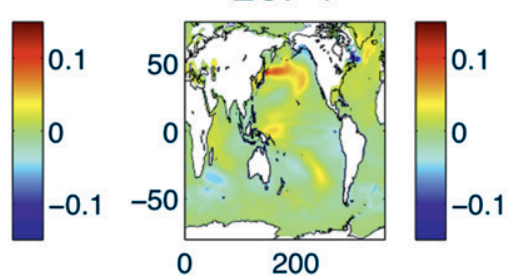

PC 1

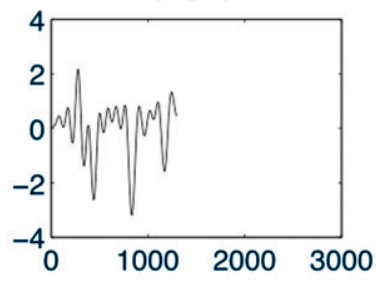

PC 3

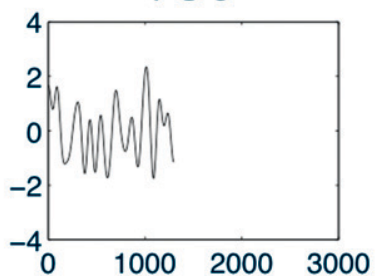

PC 2

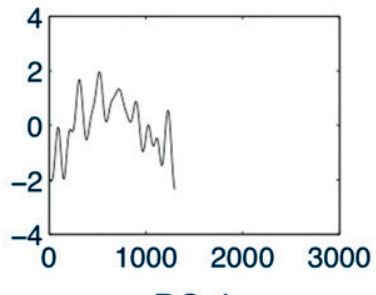

PC 4

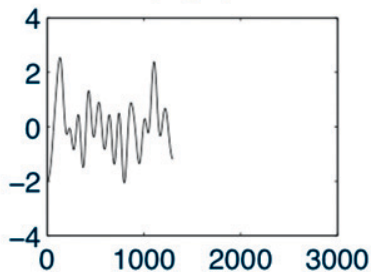

FIG. 2. As in Fig. 1, but for the NCAR CCSM4. Variances explained are 21.9\%, 18.2\%, 11.3\%, and 9.2\% for EOF1, EOF2, EOF3, and EOF4, respectively. 
EOF 1

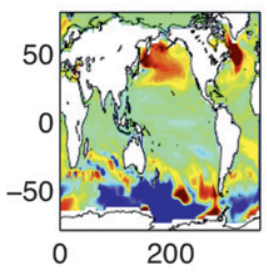

EOF 3

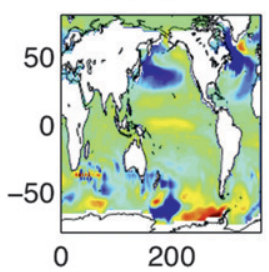

EOF 2
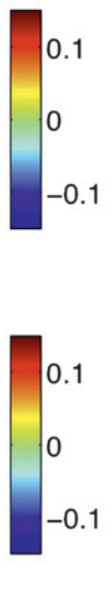

EOF 4
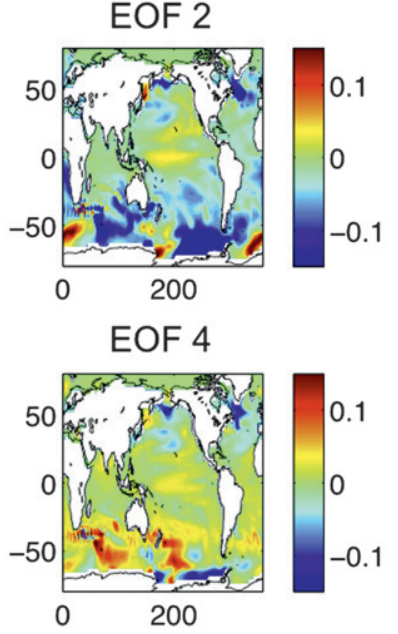

PC 1
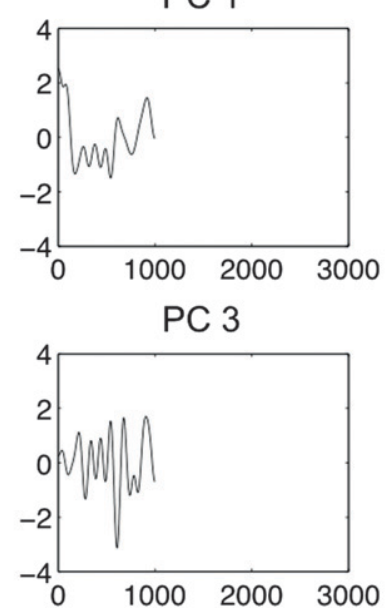

PC 2
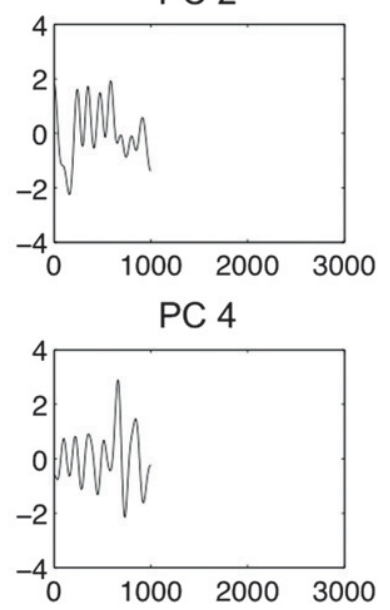

FIG. 3. As in Fig. 1, but for the ECHO-G model. Variances explained are 35.0\%, 22.4\%, 10.7\%, and 5.3\% for EOF1, EOF2, EOF3, and EOF4, respectively.

the aforementioned models. Three-member ensemble means were formed from each model's twentiethcentury simulations, the Twentieth-Century Climate in Coupled Model (20C3M) (all forcing), while one run was available for each of the future scenario experiments [scenarios A1B and A2 of the Special Report on Emissions Scenarios (SRES), related to Intergovernmental Panel on Climate Change (IPCC) Fourth Assessment Report (AR4), and the Coupled Model Intercomparison Project, phase 3 (CMIP3)]. In lieu of
AR4-coordinated future scenario experiments SRES A1B and A2, which predate the new NCAR CCSM4, we use a twentieth-century simulation wherein atmospheric $\mathrm{CO}_{2}$ concentration was ramped by $1 \% \mathrm{yr}^{-1}$ beginning in 1850 . This $\mathrm{CO}_{2}$-ramping experiment is similar to a high-emissions future scenario, such as A2, except beginning in 1850 rather than 2000.

For comparison with the aforementioned simulations, we also employ three widely used observational datasets of historical SST, including the Met Office Hadley

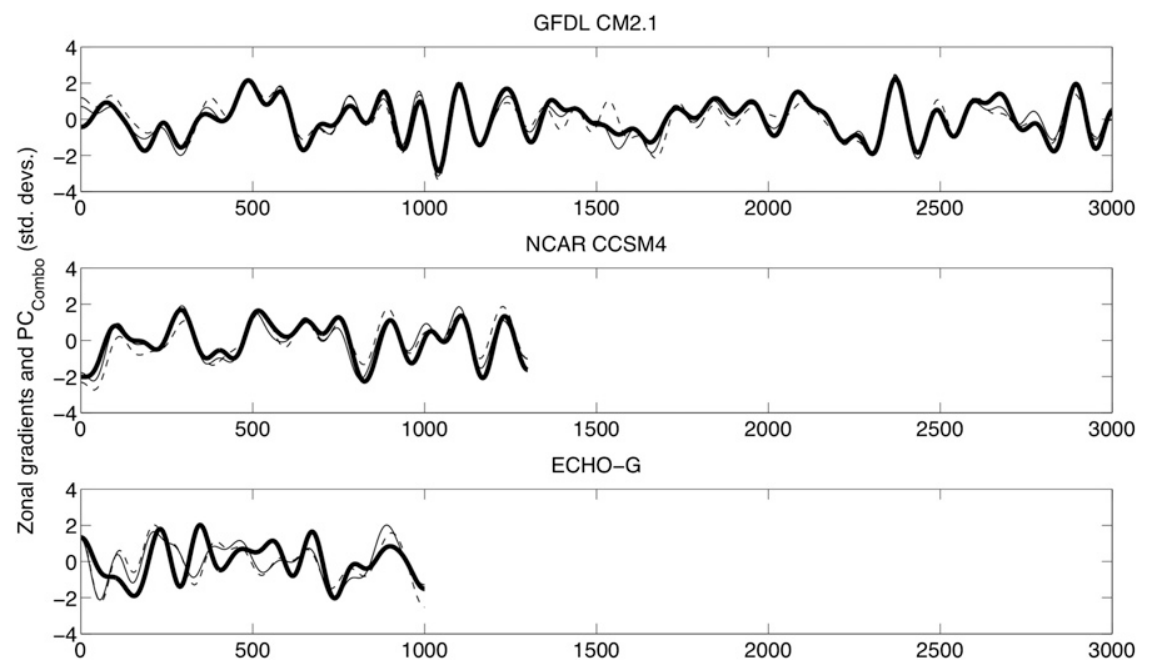

FIG. 4. Filtered (90-yr low pass) zonal SST gradient (thin solid line), zonal SLP gradient (thin dashed line), and a linear combination of the PCs corresponding to EOFs that project onto the tropical Pacific Ocean (thick solid line) from the (top) GFDL CM 2.1, (middle) NCAR CCSM4, and (bottom) ECHO-G models. Used in constructing the thick solid line were PC3 and PC4 for GFDL CM2.1 (21.7\% total variance explained); PC1, PC2, and PC4 for NCAR CCSM4 (49.3\% total variance explained); and PC2-PC4 for ECHO-G (38.4\% total variance explained). Each time series is expressed as standard deviations. 

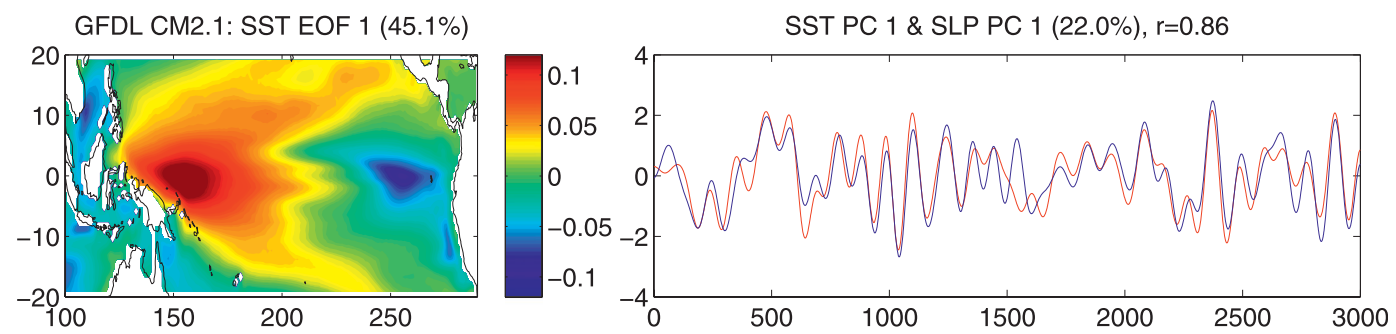

NCAR CCSM4: SST EOF $1(44.5 \%)$
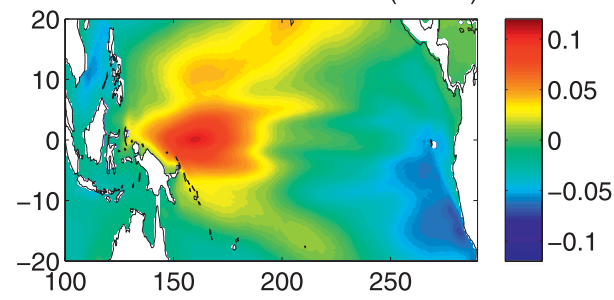

SST PC 1 \& SLP PC $1(20.6 \%), r=0.86$
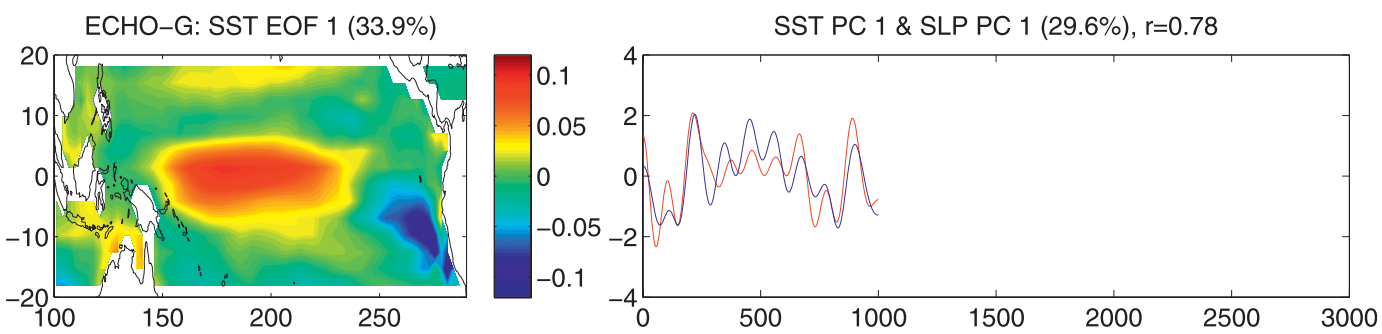

FIG. 5. (left) Leading EOF of filtered (90-yr low pass) SST in the tropical Pacific domain. (right) Leading PCs of filtered tropical Pacific SST (red) and SLP (blue). EOFs are expressed in ${ }^{\circ} \mathrm{C}$ per standard deviation, and PCs are expressed in standard deviations.

Centre Sea Ice and Sea Surface Temperature version 1 (HadISST1; Rayner et al. 2003), the National Oceanic and Atmospheric Administration (NOAA) Extended Reconstructed SST version 3b (ERSSTv3b; Smith et al. 2008), and the Kaplan Extended SST (Kaplan et al.1998). The horizontal resolutions of HadISST1, ERSSTv3b, and Kaplan are $1^{\circ}, 2^{\circ}$, and $5^{\circ}$, respectively.

\section{Results}

We begin with a general approach to identifying global patterns of unforced climate variability in three coupled climate models. Based on those results, we then carry out additional analyses focusing on characterizing the centennial variability in the tropical Pacific and linkages with the extratropics. Finally, we discuss a proposed mechanism for the unforced centennial oscillation in the tropical and extratropical Pacific.

\section{a. Patterns of unforced centennial variability}

The leading empirical orthogonal functions (EOFs) and associated principal components (PCs) of filtered (90-yr low pass) SST in the global domain from the
GFDL CM2.1, NCAR CCSM4, and ECHO-G models are shown in Figs. 1-3, respectively (the variances explained by each EOF are provided in the figure captions). In the GFDL CM2.1 simulation, the first two EOFs describe low-frequency SST variability across the high latitudes of either hemisphere. In contrast, the zonally asymmetric patterns described by EOFs 3 and 4 project strongly onto the zonal SST gradient in the equatorial Pacific, suggestive that the dominant pattern of centennial variability in the tropical Pacific is a zonal dipole with a strong counterpart in the extratropical North Pacific. It is important to note the difference between the patterns produced by this EOF analysis and the pattern associated with ENSO variability on the interannual time scale. The latter is manifest primarily in east (or central) equatorial Pacific SST anomalies with a typically negligible response in the far west, whereas the centennial pattern includes particularly strong SST anomalies in the western equatorial Pacific as well as the east. The similarities between EOF3 and EOF4 in the GFDL CM2.1 simulation are suggestive of a single, propagating all-Pacific mode. While the order of modes extracted from EOF analysis is not expected to match 
SST Comp. on LP Zonal SST Grad. SLP Comp. on LP Zonal SST Grad.
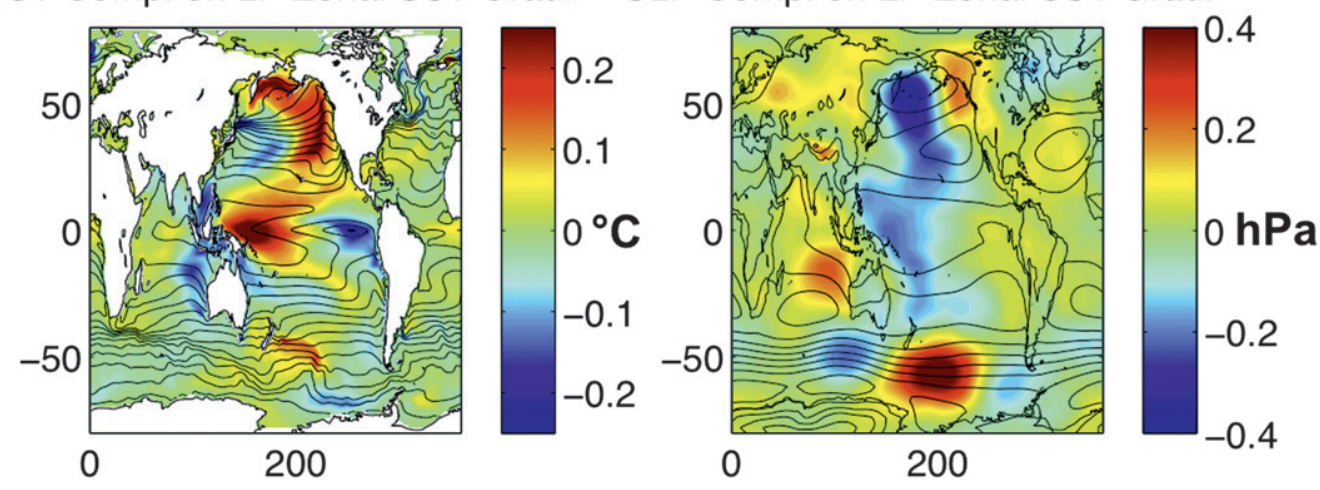

T(z) Comp. on LP Zonal SST Grad.

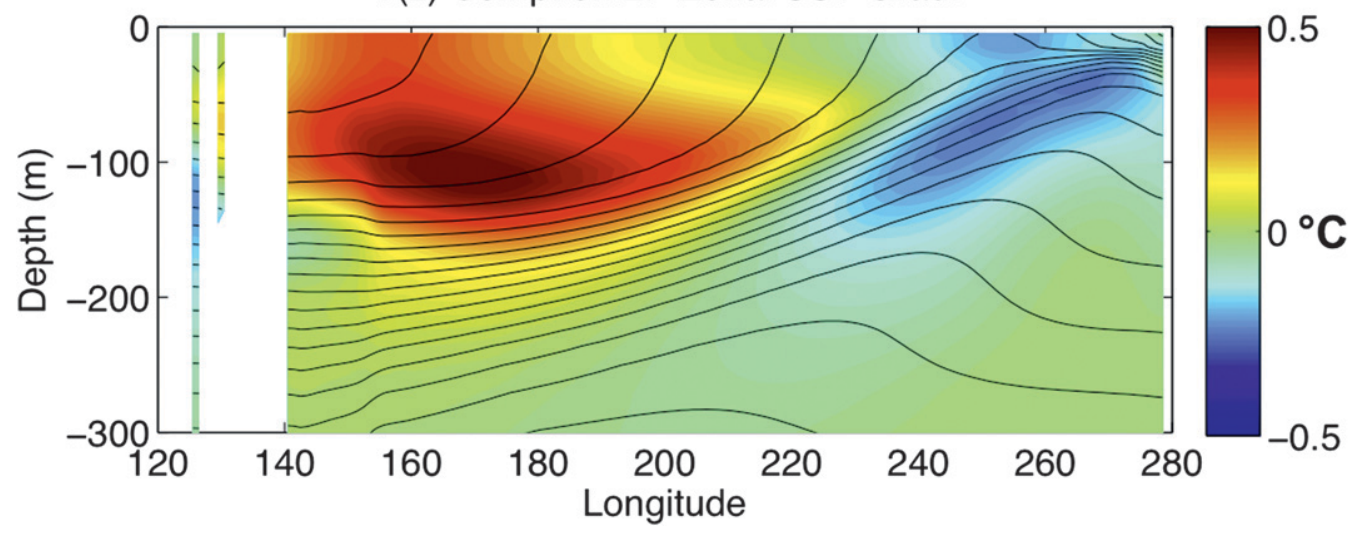

FIG. 6. GFDL CM2.1 model fields composited on the filtered (90-yr low pass) zonal SST gradient. Composite fields were computed as the difference between the mean of all unfiltered fields concurrent with the low-pass-filtered zonal SST gradient exceeding +0.5 standard deviations minus the mean of all unfiltered fields concurrent with the low-pass filtered zonal SST gradient falling below -0.5 standard deviations. Fields shown are (top left) SST $\left({ }^{\circ} \mathrm{C}\right)$, (top right) SLP (hPa), and (bottom) equatorial ocean temperatures to $300 \mathrm{~m}\left({ }^{\circ} \mathrm{C}\right)$. Contour lines indicate the background climatology for each field (contour labels omitted for clarity).

model by model, variations of the zonal gradients in the tropical Pacific are also a dominant mode of global centennial climate variability in the NCAR CCSM4 and ECHO-G models. Note, for example, the similarity between EOF3 from the GFDL CM2.1 simulation and EOF1 of the NCAR CCSM4 simulation.

To test the robustness and relevance of the global EOF analysis, linear combinations of PCs associated with EOFs that project onto the equatorial Pacific zonal SST gradient can be constructed and compared with low-pass-filtered time series of the zonal SST and SLP gradients in the equatorial Pacific in each model. Linear combinations were constructed using $\mathrm{PC} 3$ and $\mathrm{PC} 4$ from the GFDL CM2.1; PC1, PC2, and PC4 from the NCAR CCSM4; and PC2, PC3, and PC4 from the ECHO-G model. Following Karnauskas et al. (2009), an index of the zonal SST gradient is defined as the difference between SST averaged within the western equatorial Pacific $\left(5^{\circ} \mathrm{S}-5^{\circ} \mathrm{N}, 150^{\circ} \mathrm{E}-160^{\circ} \mathrm{W}\right)$ and the eastern equatorial
Pacific $\left(5^{\circ} \mathrm{S}-5^{\circ} \mathrm{N}, 130^{\circ}-80^{\circ} \mathrm{W}\right)$. The zonal SLP gradient is computed using the same areas; however, the sense of the difference is reversed, such that a large positive value corresponds with a strong zonal SLP gradient. The zonal SST and SLP gradients in each model can, in fact, be well described by the linear combination of PCs that project onto the zonal SST gradient as indicated by the high correlations among them (Fig. 4), implying that these empirical modes of variability involving large spatial scales contribute substantially to the centennial variability in the equatorial Pacific zonal SST gradient. Furthermore, the correlations between low-pass-filtered zonal SST and SLP gradients are near unity in each model, suggesting strong ocean-atmosphere coupling at the centennial time scale.

Having established the global context of centennial SST variability and the potential significance of the tropical Pacific, the above low-pass-filtered EOF analysis was repeated but with the analysis domain limited 
SST Comp. on LP Zonal SST Grad. SLP Comp. on LP Zonal SST Grad.
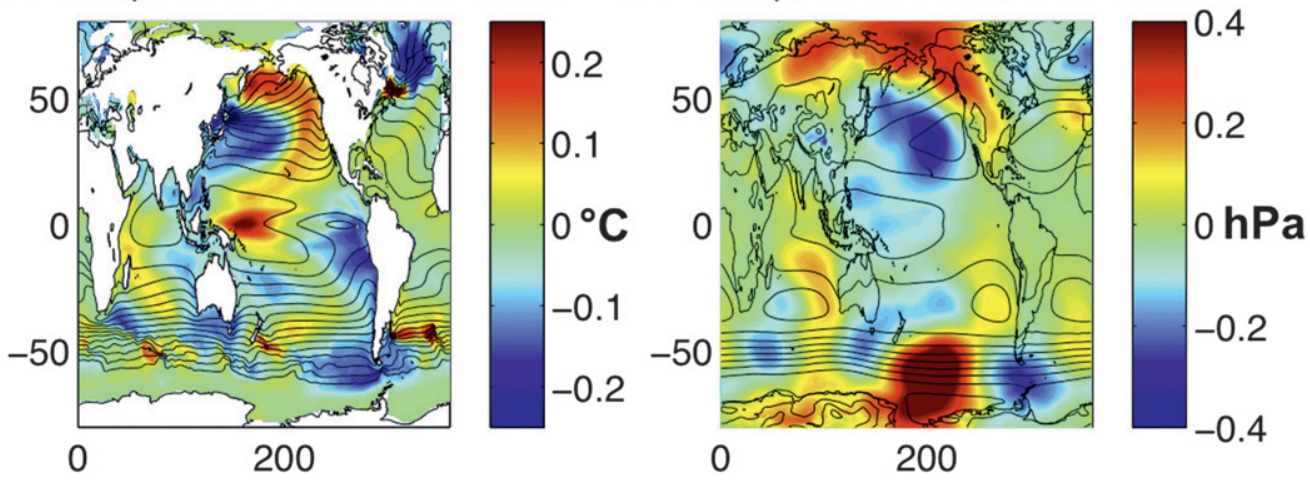

T(z) Comp. on LP Zonal SST Grad.

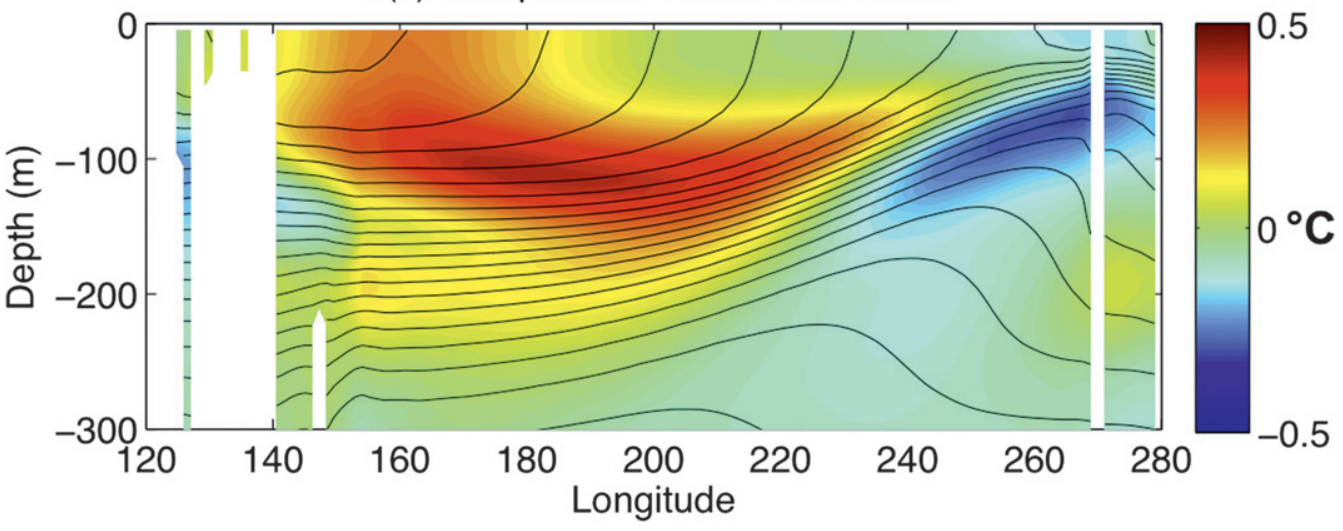

FIG. 7. As in Fig. 6, but for the NCAR CCSM4

to the tropical Pacific $\left(20^{\circ} \mathrm{S}-20^{\circ} \mathrm{N}, 100^{\circ} \mathrm{E}-70^{\circ} \mathrm{W}\right)$. The results, shown in Fig. 5, reveal that the leading mode of centennial SST variability in the tropical Pacific is a zonal dipole mode that is dissimilar to ENSO, in that there is a high-amplitude loading in the western equatorial Pacific where ENSO variance tends to be small. Furthermore, the patterns derived from the tropical Pacific-only EOF analysis share many similarities with the global EOFs, suggesting that this is a fundamental mode in the models. The centennial oscillation is a robust mode in each model $(34 \%-45 \%$ variance explained and relatively insensitive to domain boundaries) and is linked to centennial variability in the tropical atmosphere, that is, highly correlated with the leading PC of low-pass-filtered SLP (correlation coefficients 0.780.86 ). There are very strong correlations between the leading PCs' tropical Pacific-only fields (Fig. 5) and the global EOF-based time series and zonal gradients shown in Fig. 4. The spatial pattern of centennial SST anomalies also is similar among the three models despite the dipole structure being compressed zonally in the ECHO-G model relative to the other two models (i.e., the western Pacific maximum is translated eastward by $\sim 50^{\circ}$ longitude). Since the spatial pattern of the centennial oscillation in the tropical Pacific projects very strongly onto the zonal SST gradient in all three analyzed model simulations, it is important to understand the global consequences and physical mechanisms of the oscillation.

To characterize the global spatial patterns associated with the simulated centennial variability in the equatorial Pacific zonal gradients, Figs. 6-8 show the unfiltered (annually resolved) SST, SLP, and equatorial subsurface temperature fields composited on the filtered (90-yr low pass) zonal SST gradient time series for each model (a threshold of 0.5 standard deviations was used, but the results are insensitive to this choice between $\sim 0$ and 1 standard deviations). The broad features of the composite fields are highly consistent between each simulation. The difference in composite SST fields for strong minus weak low-pass-filtered zonal gradients are characterized by approximately $0.2^{\circ} \mathrm{C}$ positive and negative anomalies in the western and eastern equatorial Pacific, respectively. The composite equatorial subsurface ocean temperature fields for each model are also very similar, indicating warm (cold) anomalies at $~ 100-\mathrm{m}$ depth 
SST Comp. on LP Zonal SST Grad. SLP Comp. on LP Zonal SST Grad.
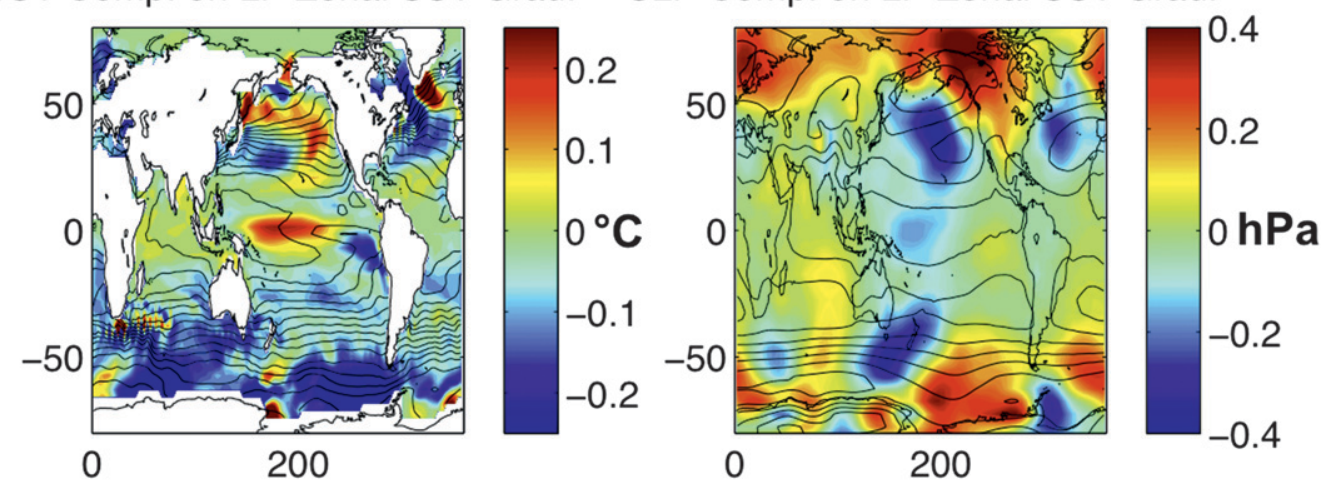

T(z) Comp. on LP Zonal SST Grad.

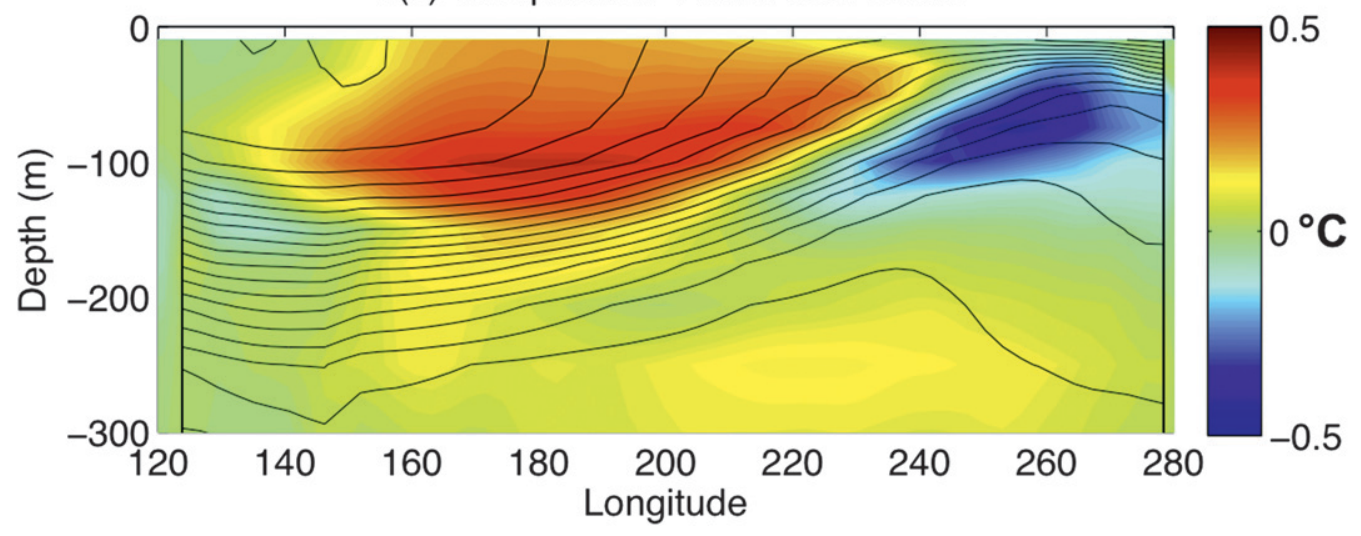

FIG. 8. As in Fig. 6, but for the ECHO-G model.

in the western (eastern) equatorial Pacific of $+0.3^{\circ} \mathrm{C}$ $\left(-0.3^{\circ} \mathrm{C}\right)$, which are indicative of anomalous heat content in the warm pool and a shallower thermocline in the cold tongue. In the ECHO-G model, the warm anomaly in the western equatorial Pacific is shifted $5^{\circ}-10^{\circ}$ eastward relative to the GFDL CM2.1 or the NCAR CCSM4, yet the subsurface temperature anomalies are similar.

Also shown in Figs. 6-8 are composite SLP fields, which demonstrate further agreement among each model in terms of the atmospheric circulation associated with low-frequency periods of strong or weak zonal SST gradients. Consistent with the sense of the composite differencing (strong - weak), the zonal SLP gradient in the equatorial Pacific is also strengthened, and a hemispherically symmetric wave pattern of alternating highs and lows emanating from the western tropical Pacific and extending well into the midlatitudes of both hemispheres is seen in the composite SLP field of each model. This is consistent with the well-known atmospheric response to tropical SST and heating anomalies (Hoskins and Karoly 1981; Webster 1981), with ENSO having notable hemispheric symmetry (Trenberth et al. 1998;
Seager et al. 2003, 2005a). The familiar poleward- to eastward-propagating Rossby wave trains in the composites are present, but systematically shifted westward in keeping with the westward-shifted location of the composite maximum tropical SST anomalies relative to the canonical ENSO pattern. The horseshoe pattern of SST anomalies in the extratropical North Pacific (and to a lesser extent, South Pacific) is also consistent with the expected quasigeostrophic circulation about the SLP anomalies found at $\sim 50^{\circ}$ latitude in the extratropics. In the NCAR CCSM4, the extratropical SST response is less strong than in the GFDL CM2.1 relative to the tropical signal, which is consistent with the differences between these two models in the position and strength of the low SLP anomaly in the extratropical North Pacific.

Some differences between the models in the centennial SST patterns analyzed here may be partially attributed to differences or biases in the mean climatology simulated by each model. While the warm SST response in the equatorial Pacific appears farther east in the ECHO-G model than in the GFDL CM2.1 or NCAR CCSM4, the warm anomaly in each model is found near 

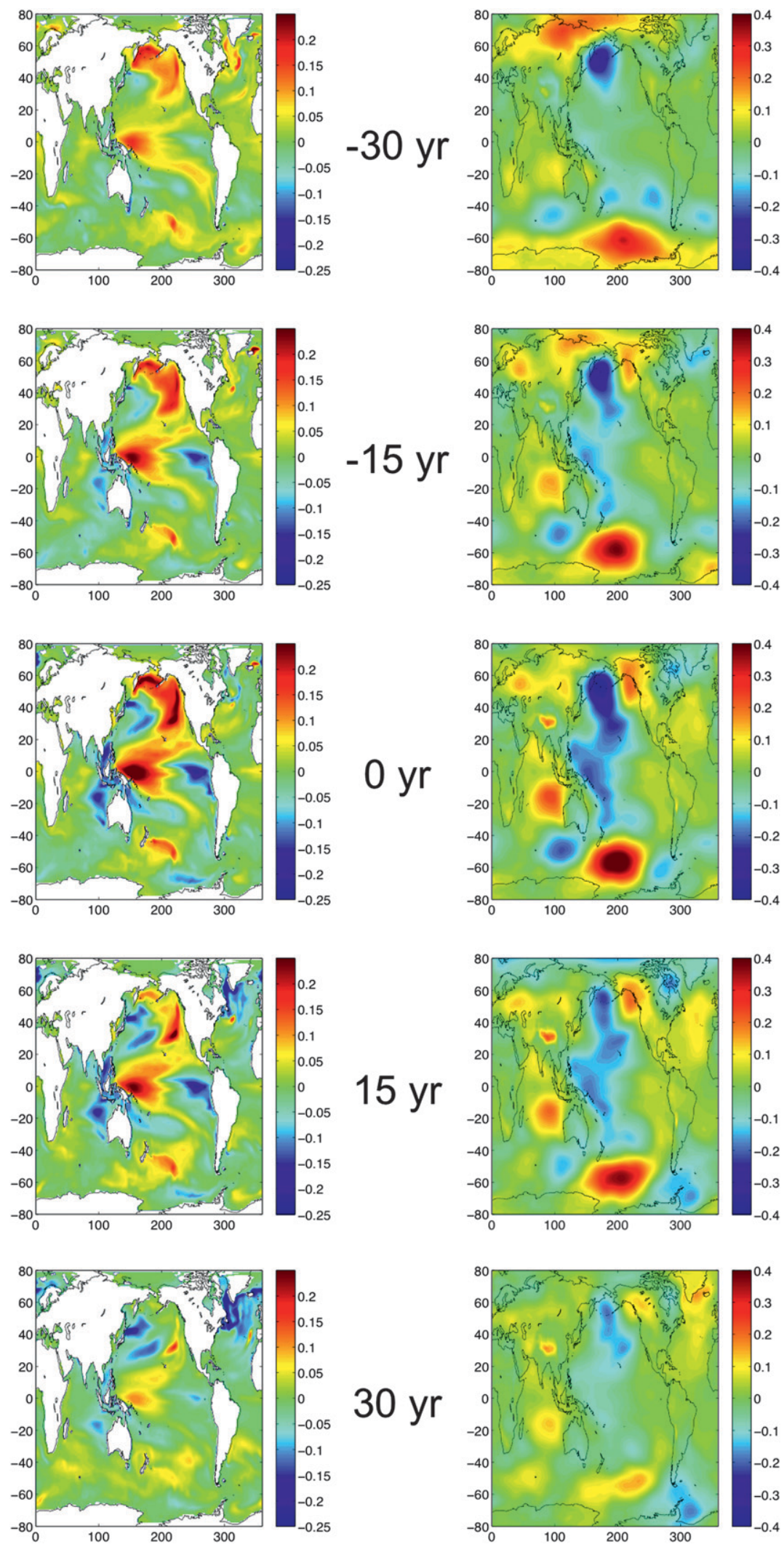

FIG. 9. As in Fig. 6 (GFDL CM2.1), but for composites of (left) SST and (right) SLP on the low-pass-filtered zonal SST gradient time series leading and lagging by several decades. 

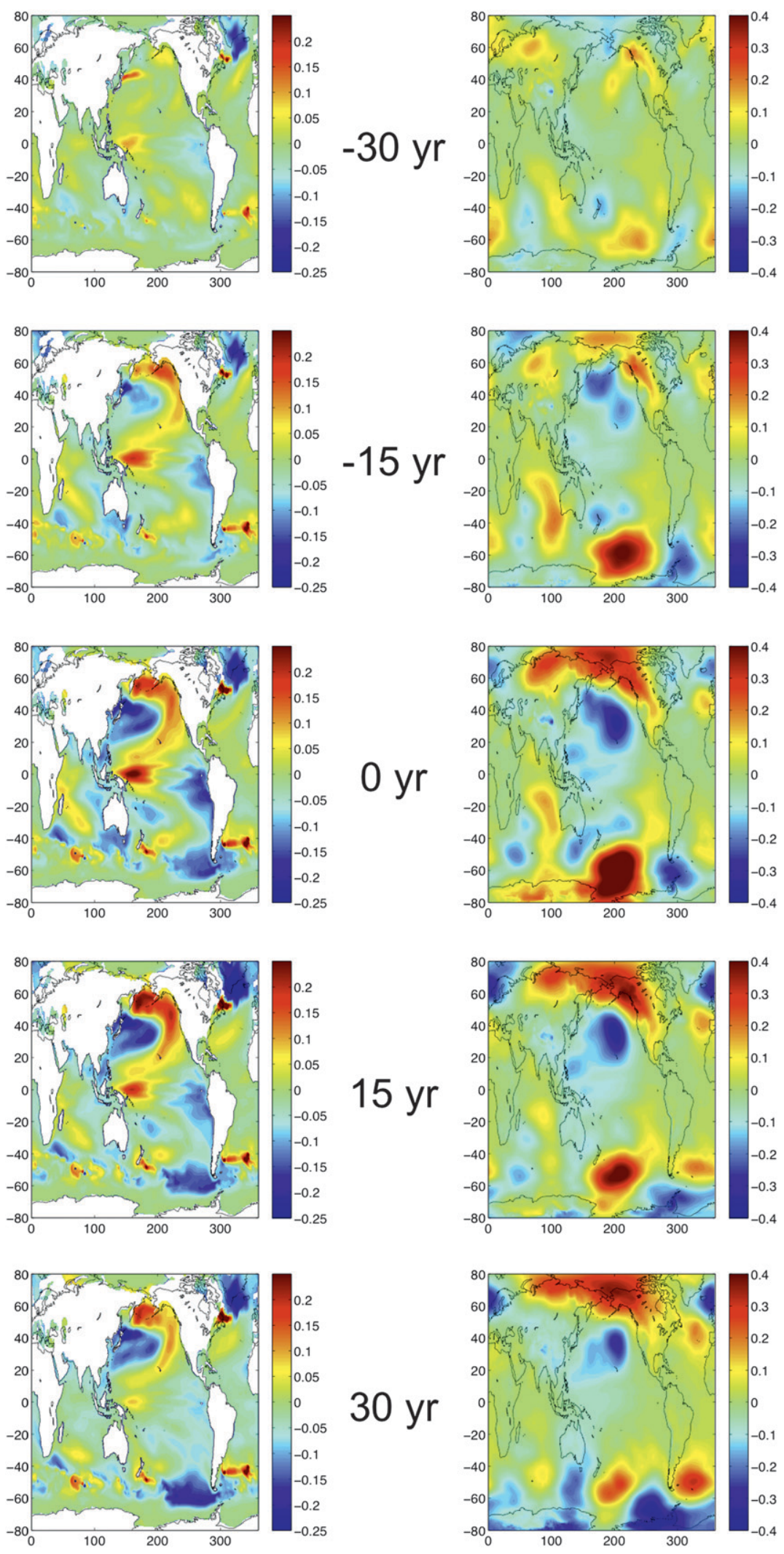

FIG. 10. As in Fig. 9, but for the NCAR CCSM4. 

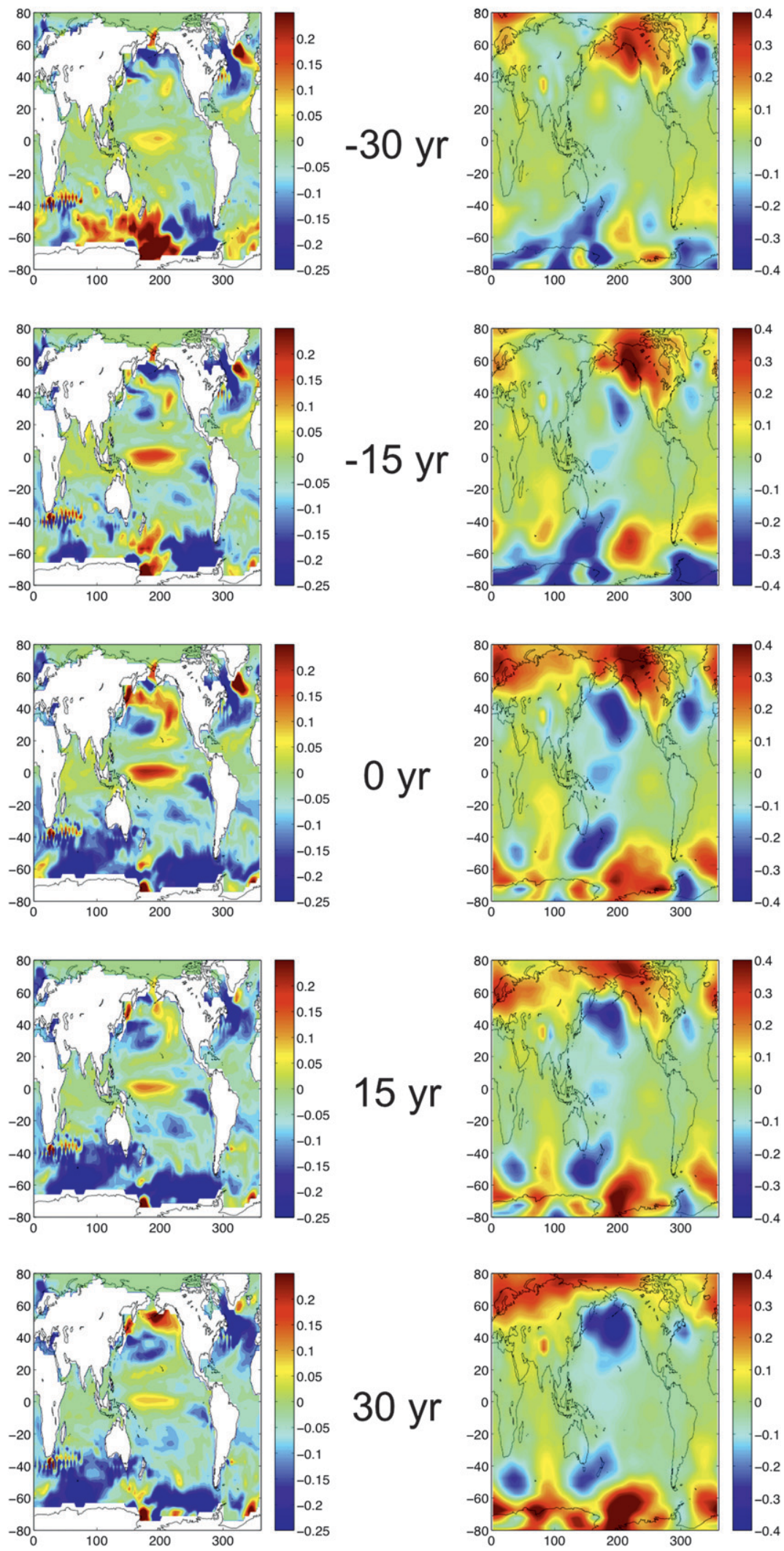

FIG. 11. As in Fig. 9, but for the ECHO-G model. 


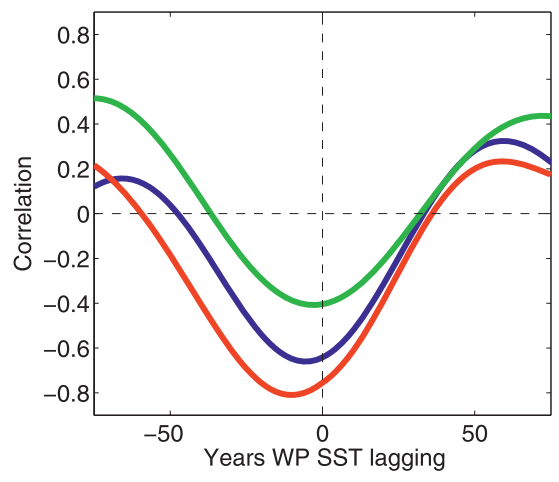

FIG. 12. Cross-correlation function between filtered (90-yr low pass) SST in the western and eastern equatorial Pacific for the GFDL CM2.1 (blue), NCAR CCSM4 (green), and ECHO-G (red) models. Negative values along the $x$ axis indicate that the west is leading the east.

the eastern edge of the warm pool. Furthermore, while the cold SST anomaly in the ECHO-G model appears to be in closer proximity to the South American coast, the pattern in each model matches that model's rendition of the coastal upwelling/cold tongue complex. For example, in the GFDL CM2.1, the mean cold tongue appears disconnected from the coastal upwelling, similar to the pattern of centennial SST anomalies.

The temporal evolution of the centennial pattern in each model is shown by way of lead-lag composite maps of SST and SLP (Figs. 9-11). Consistent across each model, the western equatorial Pacific and extratropical SST anomalies begin developing several decades (30 years or more) prior to the peak phase, and the SST anomalies in the eastern equatorial Pacific appear to

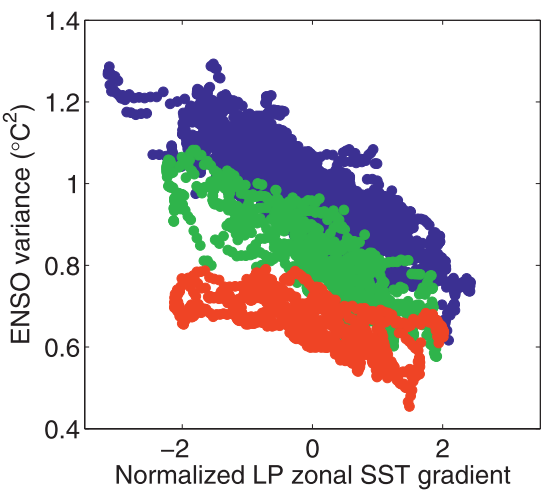

FIG. 13. Scatter diagram comparing the filtered (90-yr low pass) zonal SST gradient (normalized) and 50-yr running variance of unfiltered Niño-3 SST anomalies $\left({ }^{\circ} \mathrm{C}^{2}\right)$ for the GFDL CM2.1 (blue), NCAR CCSM4 (green), and ECHO-G (red) models.

emerge later, close to when the peak phase is reached (within $\sim 15$ years). The hemispherically symmetric pattern in SLP anomalies emerges in close alignment with the extratropical SST anomalies, consistent with the direct atmospheric forcing of the ocean. Also consistent with the robust result that the western equatorial Pacific and extratropical North Pacific begin warming several decades in advance of the peak zonal SST gradient, the cross correlation between low-pass-filtered SST anomalies in the western and eastern equatorial Pacific indicates a multiyear lag in each model (Fig. 12). The lag of the eastern equatorial Pacific relative to the west achieves a maximum value of $\sim 13$ years in the ECHO-G model, the largest lag among the three analyzed model simulations.
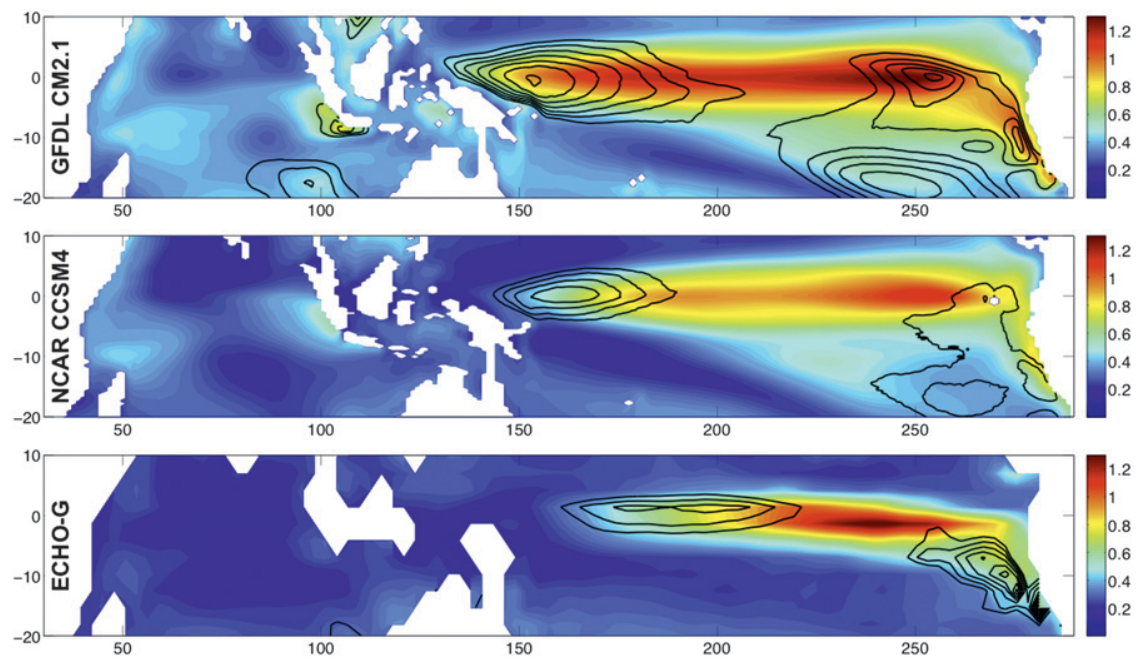

FIG. 14. Standard deviation of unfiltered (annual; ${ }^{\circ} \mathrm{C}$; colors) and filtered (90-yr low pass; ${ }^{\circ} \mathrm{C}$; contours) SST for the (top) GFDL CM2.1, (middle) NCAR CCSM4, and (bottom) ECHO-G models. Contour lines begin with $0.08^{\circ} \mathrm{C}$, interval $0.01^{\circ} \mathrm{C}$. 

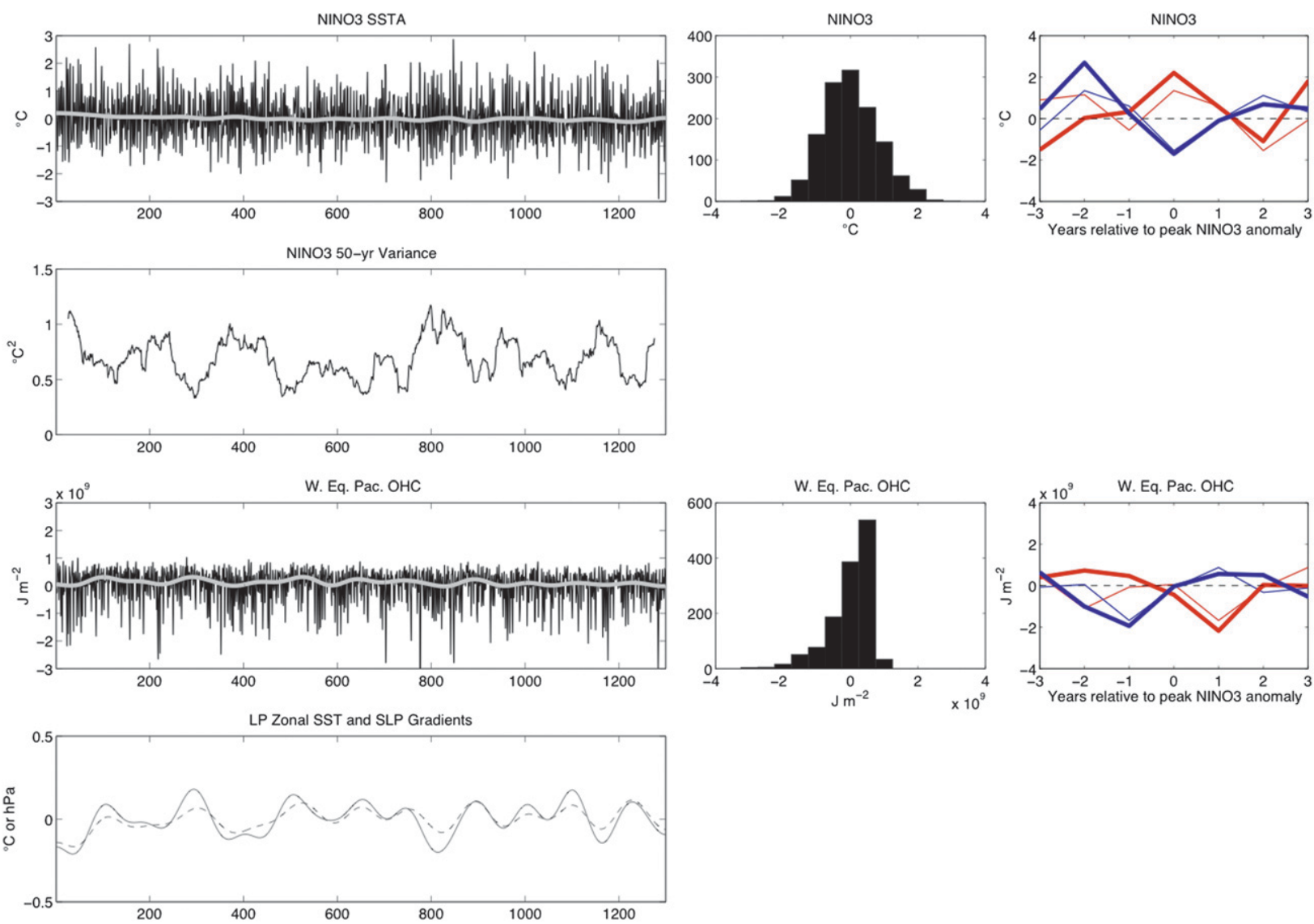

FIG. 15. (first row) Time series of unfiltered and filtered (90-yr low pass) Niño-3 SST anomaly $\left({ }^{\circ} \mathrm{C}\right)$, histogram of unfiltered Niño-3 SST anomaly, and composite evolution of unfiltered Niño-3 SST anomaly for moderate El Niño events (peak Niño-3 $>1.5$ standard deviations, thin red line), strong El Niño events (peak Niño-3 $>2$ standard deviations, thick red line), moderate La Niña events (peak Niño-3 $<1.5$ standard deviations, thin blue line), and strong La Niña events (peak Niño-3 $<2$ standard deviations, thick blue line). (second row) Time series of running variance $\left(50\right.$-yr window, ${ }^{\circ} \mathrm{C}^{2}$ ) of unfiltered Niño-3 SST anomaly. (third row) As in (first row), but for OHC (300 m) heat content in the western equatorial Pacific. (fourth row) Time series of filtered zonal SST gradient $\left({ }^{\circ} \mathrm{C}\right)$ and zonal SLP gradient (hPa). All results shown are for the NCAR CCSM4.

\section{b. A proposed mechanism}

Given the predominance of a mode of interannual variability in the tropical Pacific that is zonally asymmetric, it is natural that our effort to diagnose the mechanisms for the simulated patterns of centennial variability begins with a consideration of ENSO. In particular, it is interesting to note the simulated covariability between ENSO variance and the mean zonal SST gradient at the centennial time scale (Fig. 13). Although the overall amplitude of interannual variability varies considerably between each model, the linear association is quite similar; that is, periods of strong ENSO variability are associated with periods of weak zonal SST (and SLP) gradients, and vice versa (note discussion in Wittenberg 2009). If the simulated pattern of centennial SST variability (i.e., Figs. 6-8) resembled that of ENSO, then one might conclude that the apparent centennial variability is simply a statistical rectification of a higher-frequency oscillation that is asymmetric in amplitude (i.e., absolute SST anomalies are greater for El Niño than La Niña). This is clearly not the case, given the robust centennial SST signal in the warm pool region where ENSO-related SST anomalies are actually minimal. Nevertheless, the proposed mechanism begins to emerge in a comparison between the spatial patterns of centennial variability with that of interannual ENSO variability (Fig. 14). Within the tropics, the regions of maximum centennial SST variability are found at the western and eastern termini of the equatorial band of maximum ENSO-related SST variability. This result is robust and systematic among the three models; as the zonal extent of high interannual variability is reduced in NCAR CCSM4 relative to GFDL CM2.1, and in ECHO-G relative to NCAR CCSM4, the simulated locations of the centennial signal in the western equatorial Pacific shift accordingly. 


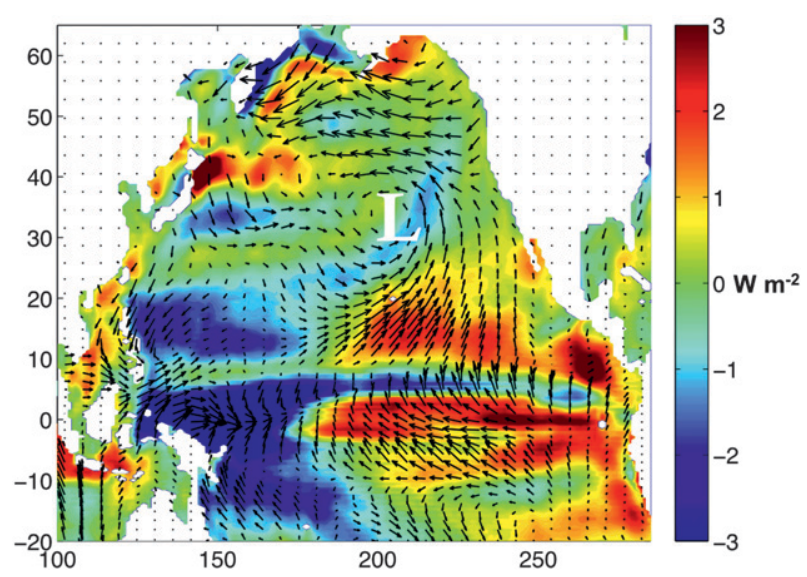

FIG. 16. Net surface heat flux (colors; $\mathrm{W} \mathrm{m}^{-2}$; positive down) and surface wind stress (vectors; dynes $\mathrm{cm}^{-2}$ ) in the tropical and extratropical North Pacific Ocean composited on the filtered (90-yr low pass) equatorial Pacific zonal SST gradient for the NCAR CCSM4. Zonal and meridional wind stress fields were degraded to one-fifth of the model resolution for clarity. Location of the low SLP anomaly evident at $\sim 30^{\circ} \mathrm{N}$ in Fig. 7 is indicated by "L."

The nonlinear nature of ENSO has previously been documented in terms of the positive skewness of SST anomalies (Deser and Wallace 1987) and asymmetries in duration, spatial variability, teleconnections, and other characteristics [see Okumura and Deser (2010), and references therein]. The asymmetry of annual ENSOrelated SST anomalies for the NCAR CCSM4 is illustrated in Fig. 15 (first row); Niño-3 SST anomalies oscillate about the mean value of zero with the warm anomalies being stronger yet shorter in duration than the cold anomalies. Also shown in Fig. 15 is a time series of the variance of Niño-3 SST anomalies within 50-yr sliding windows throughout the simulation, which indicates substantial cycles in ENSO variance over time ranging from $\sim 0.5^{\circ}$ to $1^{\circ} \mathrm{C}^{2}$.

As shown in the composite analyses of the previous subsection, the subsurface temperature anomalies in the warm pool region are the strongest part of the centennial signal. Upper-ocean heat content (OHC) anomalies were computed for the upper $300 \mathrm{~m}$ of the warm pool region (i.e., the western box used in the zonal SST gradient calculation) and are shown in Fig. 15, third row. While western equatorial Pacific $\mathrm{OHC}$ anomalies are strongly anticorrelated with Niño-3 SST anomalies, the OHC anomalies are sufficiently asymmetric that La Niña events are not capable of recharging as much $\mathrm{OHC}$ to the warm pool as is lost during El Niño events. This is particularly evident in the $\mathrm{OHC}$ anomalies throughout composite El Niño and La Niña events, also shown in Fig. 15. Therefore, during periods of strong ENSO variability, the warm pool sustains a net loss of $\mathrm{OHC}$, leading to a persistent cold SST anomaly and hence reduced zonal SST gradient.
In contrast, during periods of weak ENSO variability, the lack of recurring strong discharges of $\mathrm{OHC}$ allows the warm pool to accumulate (or at least maintain) OHC and results in a stronger zonal SST gradient. The calculations shown in Fig. 15 and throughout the remainder of this subsection are similar in their characteristics to the GFDL CM2.1 and ECHO-G model results. For brevity, we show and base our discussion on the NCAR CCSM4 results only.

As shown earlier (Figs. 9-12), the eastern equatorial Pacific centennial SST variability lags the warm pool, implying a Bjerknes (1966)-like response to the warm pool variability. This is confirmed in the composite surface heat and momentum fluxes shown in Fig. 16. During centennial periods of strong zonal SST gradient, easterly wind stress anomalies in the central equatorial Pacific drive enhanced upwelling in the cold tongue region. The SST anomalies in the tropics are clearly not driven by heat fluxes, since the sign of the anomalous net heat flux is opposite to that which would produce the pattern of a strong zonal SST gradient. Rather, the tropical net heat flux anomalies damp the SST anomalies (as is typically the case for interannual variability). In the extratropical North Pacific, the SST anomalies can be viewed as a response to the anomalous surface heat fluxes driven by cyclonic flow present in the North Pacific atmosphere. Part of the anomalous cyclonic circulation about the low SLP anomaly includes southerly winds in the northeastern Pacific across sharp meridional gradients, driving warm moist advection and reducing upward surface heat fluxes. Additionally, wind-driven anomalous ocean temperature advection and reduced offshore transport along the western coast of North America may contribute to the extratropical SST anomalies.

Finally, we note some important distinctions between the simulated tropical precipitation response to centennial variability in the zonal SST gradient and interannual ENSO variability (Fig. 17). While both the strong centennial gradient and La Niña patterns include a broad region of reduced precipitation extending from South America toward the west-central Pacific, the dry anomaly extends much farther westward during La Niña, whereas the dominant precipitation anomaly associated with a strong centennial gradient is positive over the warm pool. Also, during La Niña, precipitation tends to be enhanced over the entire Maritime Continent extending into the eastern Indian Ocean, while the enhanced rainfall associated with the strong centennial gradient is entirely confined to the Pacific basin, which is consistent with the centennial pattern of OHC and SST anomalies. Although weaker than the tropical precipitation anomalies, a positive precipitation anomaly in the extratropical North Pacific can be identified that is collocated with the 

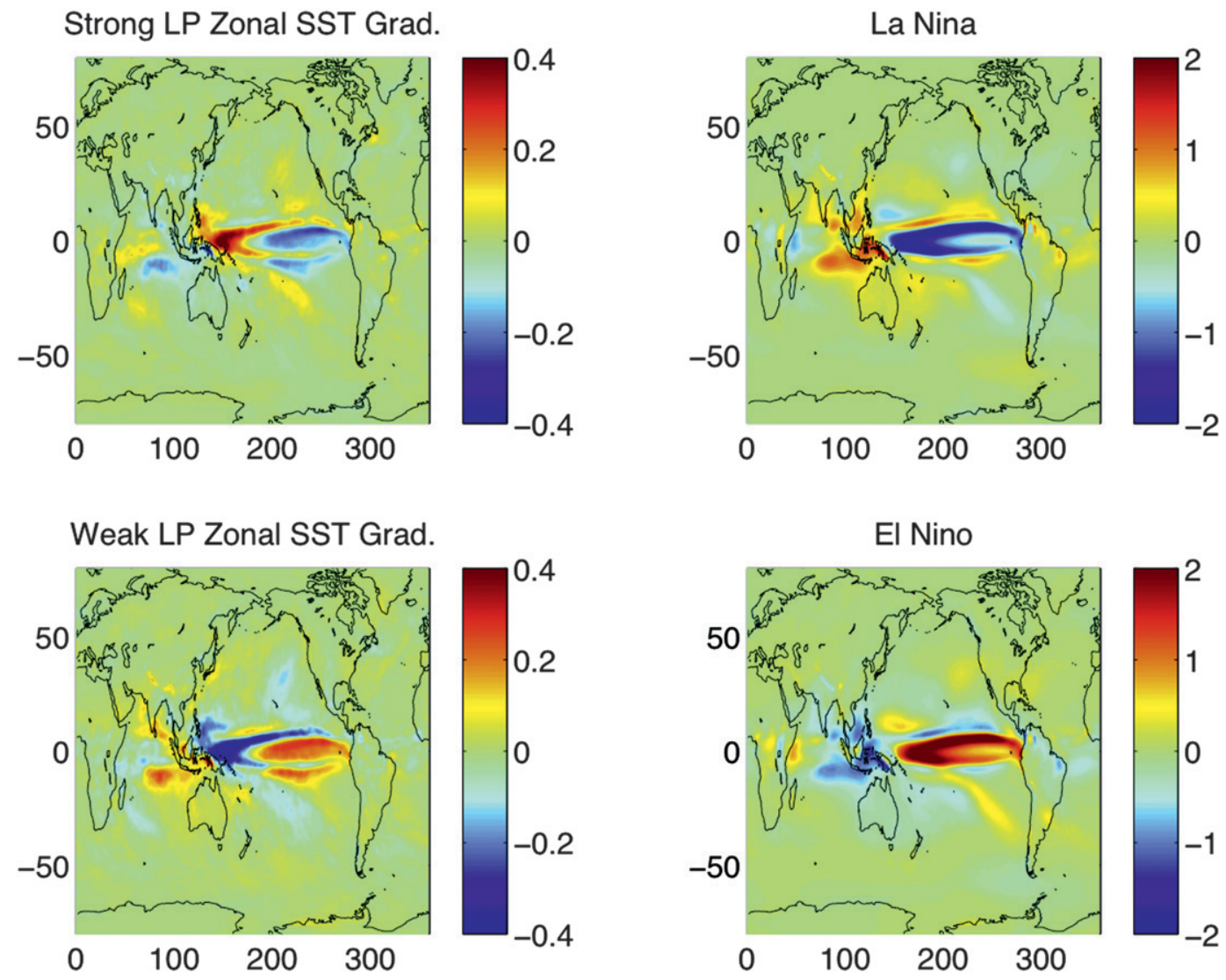

FIG. 17. Precipitation ( $\mathrm{mm}_{\text {day }}{ }^{-1}$ ) composited on the (left) filtered (90-yr low pass) zonal SST gradient and (right) unfiltered Niño-3 SST anomaly for the NCAR CCSM4.

composite low SLP anomaly in Fig. 7 and the negative net surface heat flux anomaly in Fig. 16. Over North America, the ENSO-precipitation teleconnection is quite realistic (not shown) and displays notable differences from the centennial precipitation pattern, which are also likely caused by the differences in SST patterns.

\section{Implications for forced-trend detection}

The simulated centennial variability in the long unforced simulations analyzed here has implications for forced-trend detection in recent and future decades and centuries. Shown in Fig. 18 are time series of the zonal SST gradient from observations over the twentieth century, along with forced simulations of the twentieth and twenty-first centuries from each of the models analyzed here. Trends including uncertainties are provided in Table 1. Observational estimates of the trends in the zonal SST gradient range from $-0.02^{\circ}$ to $+0.15^{\circ} \mathrm{C}$ century $^{-1}$; none of these trends based on annual time series is statistically significant. Although the trends in the zonal SST gradient over the twentieth century from each model are positive, none are statistically significant given the large interannual and decadal variability (note that the trends in Table 1 are computed on annual time series, not on the decadally smoothed time series that are shown in Fig. 18). Over the twenty-first century, the models analyzed here disagree on the sign of change in the zonal SST gradient; the GFDL CM2.1 predicts a $0.60^{\circ} \mathrm{C}$ century ${ }^{-1}\left(0.38^{\circ} \mathrm{C}\right.$ century $\left.^{-1}\right)$ increase in the zonal SST gradient, while the ECHO-G model predicts a $0.23^{\circ} \mathrm{C}$ century $^{-1}\left(0.26^{\circ} \mathrm{C}\right.$ century $\left.{ }^{-1}\right)$ decrease in the zonal SST gradient under the A1B (A2) emissions scenario. In response to an increase of $\mathrm{CO}_{2}$ by $1 \% \mathrm{yr}^{-1}$ beginning in 1850 (20C+, Table 1), the NCAR CCSM4 predicts a $0.29^{\circ} \mathrm{C}$ century ${ }^{-1}$ decrease in the zonal SST gradient, similar to the ECHO-G result.

How the trends shown in Fig. 18 and Table 1 compare to those arising entirely from unforced, internal climate dynamics is illustrated in Fig. 19. Each vertical bar along the time axis represents the linear trend in the unfiltered zonal SST gradient computed over a sliding 125-yr window. As expected, the trend time series closely resembles the low-pass-filtered time series of the zonal SST gradient 


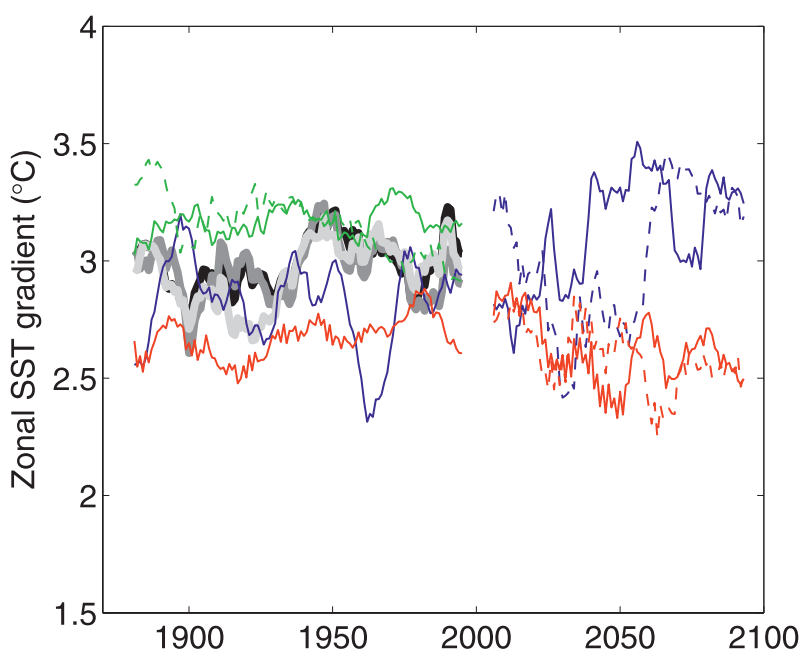

FIG. 18. Decadally smoothed time series of the zonal SST gradient from observations and model simulations of the twentieth and twenty-first centuries. Thick black and gray lines represent observations, blue lines represent the GFDL CM2.1, green lines represent the NCAR CCSM4, and red lines represent the ECHO-G model. All model lines prior to the year 2000 represent the standard 20C3M experiment (twentieth century, all forcing, ensemble mean of three runs per model), except for the dashed green line, which represents a twentieth-century experiment forced with atmospheric $\mathrm{CO}_{2}$ concentration increasing by $1 \% \mathrm{yr}^{-1}$. Beyond 2000, solid (dashed) lines represent single SRES A1B (A2) experiments.

itself, that is, Fig. 4, but with a quarter-cycle lag. Trends in the zonal SST gradient that are statistically significant at the $95 \%$ confidence level, represented by black bars, can be found throughout the unforced simulation of all three models. Each model simulates several intervals during which the simulated trend magnitude exceeds that model's simulated trend during the twentieth century, either of the future simulations, the maximum trend estimate from observations of the twentieth century, and even the maximum trend estimated by an analysis of the seasonal trends over the twentieth century (a strengthening of the September zonal SST gradient by $0.4^{\circ} \mathrm{C}$ century $^{-1}$ in the HadISST1 dataset; Karnauskas et al. 2009). If these models are correct, then it would appear that a trend in the zonal SST gradient of magnitude $\sim 0.5^{\circ} \mathrm{C}$ century $^{-1}$ is entirely within the range of unforced, internal climate variability.

An important distinction between unforced centennial variability and the forced response of tropical $\mathrm{Pa}$ cific SSTs, however, may be in the details of the spatial pattern; all models analyzed here include a maximum of centennial variability in the western equatorial Pacific, where ENSO variance is minimal. Thus, there is a clear difference between patterns of interannual and centennial Pacific variability. The distinction between the patterns of centennial variability and the forced response to rising greenhouse gases is not so clear. In the case of the forced response, all models show warming in the western equatorial Pacific with some having even more in the eastern equatorial Pacific (hence a weakening zonal gradient) and some having less (hence a strengthening zonal gradient) (Seager and Vecchi 2010). A more clear distinction may occur in the Walker circulation, which varies coherently with the zonal SST gradient in centennial variability but generally weakens in response to rising greenhouse gases in coupled models even if the zonal SST gradient strengthens. Further, the zonally asymmetric equatorial Pacific thermocline changes within centennial modes are in contrast to the additional background zonal mean shoaling that occurs in response to rising greenhouse gases (DiNezio et al. 2009). This implies that, for the unambiguous detection and attribution of tropical SST changes to external forcing, careful attention must be paid to not simply the zonal SST gradient but the entire coupled state of the tropical Pacific atmosphereocean system.

\section{Summary and concluding remarks}

Simulated internal centennial variability yields overall changes in the equatorial Pacific zonal SST gradient of roughly a half a degree Celsius. Such changes are equivalent to trends that have been estimated over the modern instrumental era since $\sim 1880$ (see references in the introduction). It should also be noted that simulated centennial variability in the tropical Pacific Ocean is no stronger than in other parts of the World Ocean and is

TABLE 1. Trends in the equatorial Pacific zonal SST gradient $\left({ }^{\circ} \mathrm{C}\right.$ century $\left.{ }^{-1}\right)$ over the twentieth century $(1876-2000)$ and the twenty-first century (2001-98) from observations and models. 20C indicates the standard 20C3M experiment, A1B (A2) indicates the SRES A1B (SRES A2) emissions scenario associated with the IPCC AR4 (single run per model), and 20C+ indicates a twentieth-century simulation where atmospheric $\mathrm{CO}_{2}$ concentration increases by $1 \% \mathrm{yr}^{-1}$ (which is similar to the $\mathrm{A} 2$ scenario, but beginning in 1850 rather than 2001 ). Linear trends and $95 \%$ confidence intervals were estimated by least squares regression.

\begin{tabular}{|c|c|c|c|c|c|c|}
\hline & HadISST1 & ERSSTv3b & Kaplan & CM2.1 & CCSM4 & ECHO-G \\
\hline $20 \mathrm{C}$ & $+0.09 \pm 0.20$ & $-0.02 \pm 0.22$ & $+0.15 \pm 0.21$ & $+0.01 \pm 0.20$ & $+0.07 \pm 0.13$ & $+0.10 \pm 0.16$ \\
\hline A1B & & & & $+0.60 \pm 0.37$ & & $-0.23 \pm 0.37$ \\
\hline A2 & & & & $+0.38 \pm 0.47$ & & $-0.26 \pm 0.41$ \\
\hline $20 \mathrm{C}+$ & & & & & $-0.29 \pm 0.13$ & \\
\hline
\end{tabular}



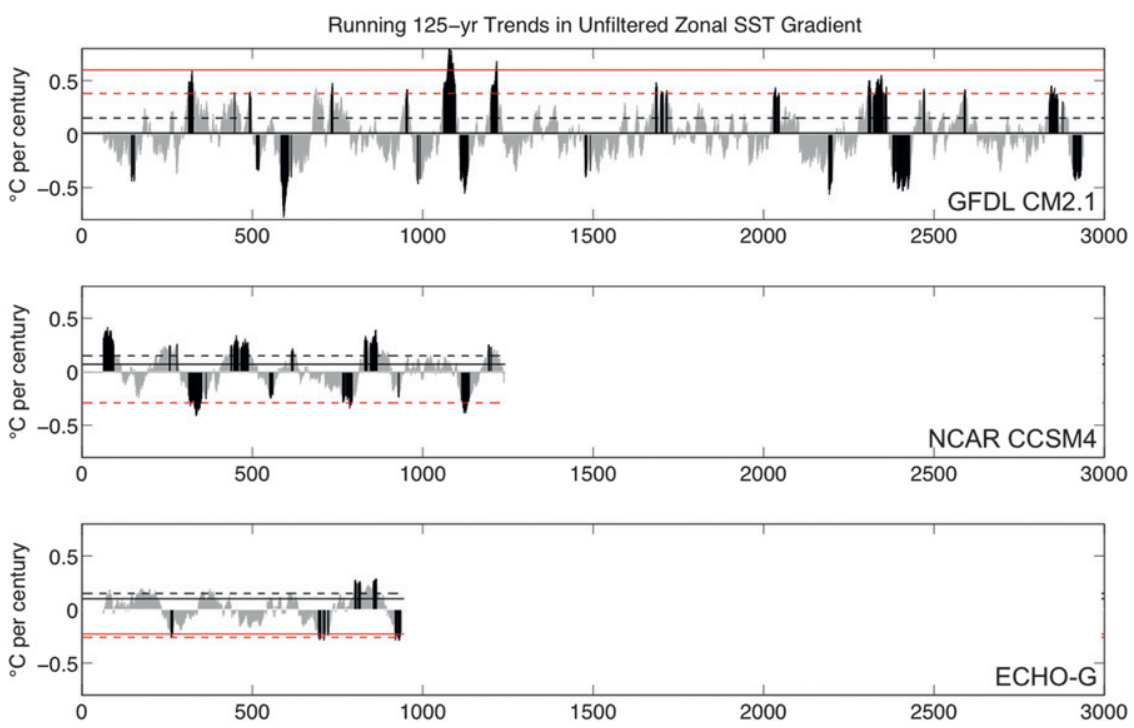

FIG. 19. Time series of running linear trends (125-yr window) in the unfiltered zonal SST gradient in the (top) GFDL CM2.1, (middle) NCAR CCSM4, and (bottom) ECHO-G models. Individual 125-yr trends that are (are not) statistically significant at the $95 \%$ confidence level are indicated in black (gray). Also shown in each panel is the model's trend over the twentieth century (solid black line) and twenty-first century (red lines) from CMIP3/IPCC AR4 simulations. Solid red line indicates the trend in the SRES-A1B experiment, while the dashed red line indicates the trend in the SRES A2 experiment (or the $1 \% \mathrm{yr}^{-1}$ ramping experiment, for the NCAR CCSM4 model). The largest of the observational trends is also indicated in each panel by a dashed black line (see Table 1 ).

actually weaker than in many high-latitude areas. The global implications of the variability, however, could be larger given the sensitivity of global atmospheric circulation to small changes in the warmest SSTs in the tropical Pacific. The simulated relationship between unforced centennial variability in the mean state and that of interannual ENSO variability can be compared with a multimodel analysis of the predicted response to anthropogenic forcing (Solomon et al. 2007), which shows no clear relationship between projected changes in the mean state and in ENSO variance. This is not a paradox, since the tropical Pacific mean state can respond to more than one mechanism. The greenhouse-forced response of the tropical Pacific mean state in IPCC AR4 simulations appears to be dominated by the overall weakening of the Walker circulation (Held and Soden 2006; Vecchi et al. 2006, Vecchi and Soden 2007), which arises independently of any change in ENSO variability. In contrast, the unforced variability of the tropical Pacific mean state in the simulations analyzed here appears to arise directly from internal variations in ENSO that occur on time scales typically longer than anthropogenic $\mathrm{CO}_{2}$-forcing simulations.

The model-based work presented here has two clear and important implications that depend on whether the model variability has a counterpart in nature:
1) If nature exhibits such strong natural variability of tropical Pacific SSTs on centennial time scales, then assumptions that the observed trend over the past century to a century and a half is a response to radiative forcing are tenuous. It could in fact be that the observed trend over the past century and a half is merely reflective of internal variability. If so, it could strengthen or weaken in the future as the natural variability evolves. This will combine with, and potentially interact with, any forced response and thus have implications for tropical Pacific and global climate.

2) If the centennial variability in the models is spurious, then it nevertheless is a robust component of the three analyzed models, is likely to exist in other models, and therefore will continue to influence coupled GCM projections of future climate, as well as initialized decadal hindcasts and forecasts conducted with GCMs. In all cases, it must be known at what stage the natural centennial variability exists at the beginning of a forecast or projection to isolate the forced change from the modeled internal variability.

Given the above-mentioned implications, our findings place a premium on efforts to develop long records of past tropical Pacific SST variability. This can only be done using paleoclimatic records, such as corals in the 
equatorial Pacific, southeastern Indian Ocean, and the South China Sea or from ocean sediment cores in regions with sedimentation rates high enough to allow adequate temporal resolution. Cane (2005) provides an earlier survey of such records, while more recent records that span a century or longer have become available from coral archives (e.g., Bagnato et al. 2005; Linsley et al. 2000, 2006; Lough 2007; Quinn et al. 2006), and sediment cores (e.g., Conroy et al. 2009). Land-based records from lakes, speleothems, and trees would also be useful to ascertain the associated hydrologic signal, although care must be taken to interpret these records, given the potential influence of SST variability in more than just the tropical Pacific. Long reconstructions of ENSO variability, such as those synthesized by McGregor et al. (2010), are also necessary to verify the proposed mechanism linking the simulated centennial oscillation in the tropical Pacific mean state to low-frequency changes in ENSO variability. Hydrologic proxies may be able to distinguish between time scales based on the divergent precipitation patterns associated with centennial and ENSO variability shown here. It therefore is a matter of significant importance, from the points of view of understanding long-term climate variability and change and the practical application of models, to determine if high-amplitude centennial variability of tropical Pacific SSTs is an inherent property of the real climate system.

Acknowledgments. The authors thank two anonymous reviewers for their insightful comments throughout the review process, and Delia Oppo for her constructive feedback on an early draft of this manuscript. KBK gratefully acknowledges support from the WHOI Ocean and Climate Change Institute (OCCI). JES and RS were supported by NOAA's Climate Variability and Predictability Program (Award NA10OAR431037). We acknowledge the modeling groups, the Program for Climate Model Diagnosis and Intercomparison (PCMDI), and the WCRP's Working Group on Coupled Modelling (WGCM) for their roles in making available the WCRP CMIP3 multimodel dataset. Support of this dataset is provided by the Office of Science, U.S. Department of Energy. Thanks especially to NOAA GFDL for providing the millennial simulation output of the GFDL CM2.1.

\section{REFERENCES}

Ammann, C. M., F. Joos, D. S. Schimel, B. L. Otto-Bliesner, and R. A. Tomas, 2007: Solar influence on climate during the past millennium: Results from transient simulations with the NCAR Climate System Model. Proc. Natl. Acad. Sci. USA, 104, 3713-3718, doi:10.1073/pnas.0605064103.
Bagnato, S., B. K. Linsley, S. S. Howe, G. M. Wellington, and J. Salinger, 2005: Coral oxygen isotope records of interdecadal climate variations in the South Pacific convergence zone region. Geochem. Geophys. Geosyst., 6, Q06001, doi:10.1029/ $2004 \mathrm{GC} 000879$.

Bjerknes, J., 1966: A possible response of the atmospheric Hadley circulation to equatorial anomalies of ocean temperature. Tellus, 18, 820-829.

Bunge, L., and A. J. Clarke, 2009: A verified estimate of the El Niño index Niño-3.4 since 1877. J. Climate, 22, 39793992.

Burgman, R., R. Seager, A. C. Clement, and C. Herweijer, 2010: Role of tropical Pacific SSTs in global medieval hydroclimate: A modeling study. Geophys. Res. Lett., 37, L06705, doi:10. 1029/2009GL042239.

Cane, M. A., 2005: The evolution of El Niño, past and future. Earth Planet. Sci. Lett., 230, 227-240.

—, A. C. Clement, A. Kaplan, Y. Kushnir, D. Pozdnyakov, R. Seager, S. E. Zebiak, and R. Murtugudde, 1997: Twentiethcentury sea surface temperature trends. Science, 275, 957-960.

Compo, G. P., and P. D. Sardeshmukh, 2010: Removing ENSOrelated variations from the climate record. J. Climate, 23, 1957-1978.

Conroy, J. L., A. Restrepo, J. T. Overpeck, M. Steinitz-Kannan, J. E. Cole, M. B. Bush, and P. A. Colinvaux, 2009: Unprecedented recent warming of surface temperatures in the eastern tropical Pacific Ocean. Nat. Geosci., 2, 46-50.

Delworth, T. L., and Coauthors, 2006: GFDL's CM2 global coupled climate models. Part I: Formulation and simulation characteristics. J. Climate, 19, 643-674.

Deser, C., and J. M. Wallace, 1987: El Niño events and their relation to the Southern Oscillation: 1925-1986. J. Geophys. Res., 92 (C13), 14 189-14 196.

— A. S. Phillips, and M. A. Alexander, 2010: Twentieth century tropical sea surface temperature trends revisited. Geophys. Res. Lett., 37, L10701, doi:10.1029/2010GL043321.

DiNezio, P. N., A. C. Clement, G. A. Vecchi, B. J. Soden, B. P. Kirtman, and S.-K. Lee, 2009: Climate response of the equatorial Pacific to global warming. J. Climate, 22, 4873-4892.

Gent, P. R., and Coauthors, 2011: The Community Climate System Model version 4. J. Climate, 24, 4973-4991.

González-Rouco, F. J., H. von Storch, and E. Zorita, 2003: Deep soil temperature as proxy for surface air-temperature in a coupled model simulation of the last thousand years. Geophys. Res. Lett., 30, 2116, doi:10.1029/2003GL018264.

_ H. Beltrami, E. Zorita, and H. von Storch, 2006: Simulation and inversion of borehole temperature profiles in surrogate climates: Spatial distribution and surface coupling. Geophys. Res. Lett., 33, L01703, doi:10.1029/2005GL024693.

_ , and Coauthors, 2011: Medieval Climate Anomaly to Little Ice Age transition as simulated by current climate models. PAGES News, No. 1, PAGES International Project Office, Bern, Switzerland, 7-8.

Graham, N. E., C. M. Ammann, D. Fleitmann, K. M. Cobb, and J. Luterbacher, 2010: Support for global climate reorganization during the "Medieval Climate Anomaly." Climate Dyn., 37, 1217-1245.

Held, I. M., and B. J. Soden, 2006: Robust responses of the hydrological cycle to global warming. J. Climate, 19, 56865699.

Hoerling, M. P., J. Eischeid, and J. Perlwitz, 2010: Regional precipitation trends: Distinguishing natural variability from anthropogenic forcing. J. Climate, 23, 2131-2145. 
Hoskins, B. J., and D. J. Karoly, 1981: The steady linear response of a spherical atmosphere to thermal and orographic forcing. J. Atmos. Sci., 38, 1179-1196.

Kaplan, A., M. Cane, Y. Kushnir, A. Clement, M. B. Blumenthal, and B. Rajagopalan, 1998: Analyses of global sea surface temperature 1856-1991. J. Geophys. Res., 103 (C9), 18 567-18 589.

Karnauskas, K. B., R. Seager, A. Kaplan, Y. Kushnir, and M. A. Cane, 2009: Observed strengthening of the zonal sea surface temperature gradient across the equatorial Pacific Ocean. J. Climate, 22, 4316-4321.

Kumar, A., B. Jha, and M. L'Heureux, 2010: Are tropical SST trends changing the global teleconnection during La Niña? Geophys. Res. Lett., 37, L12702, doi:10.1029/2010GL043394.

Legutke, S., and E. Maier-Reimer, 1999: Climatology of the HOPE-G global ocean-sea ice general circulation model. DKRZ Tech. Rep. 21, 90 pp.

_ and R. Voss, 1999: The Hamburg atmosphere-ocean coupled circulation Model ECHO-G. DKRZ Tech. Rep. 18, 62 pp.

Li, J., S.-P. Xie, E. R. Cook, G. Huang, R. D’Arrigo, F. Liu, J. Ma, and X.-T. Zheng, 2011: Interdecadal modulation of El Niño amplitude during the past millennium. Nature Climate Change, 1, 114-118.

Linsley, B. K., L. Ren, R. B. Dunbar, and S. S. Howe, 2000: El Niño Southern Oscillation (ENSO) and decadal-scale climate variability at $10^{\circ} \mathrm{N}$ in the eastern Pacific from 1893 to 1994 : A coral-based reconstruction from Clipperton Atoll. Paleoceanography, 15, 322-335, doi:10.1029/1999PA000428.

_ - A. Kaplan, Y. Gouriou, J. Salinger, P. B. deMenocal, G. M. Wellington, and S. S. Howe, 2006: Tracking the extent of the South Pacific convergence zone since the early 1600 s. Geochem. Geophys. Geosyst., 7, Q05003, doi:10.1029/2005GC001115.

Lough, J. M., 2007: Tropical river flow and rainfall reconstructions from coral luminescence: Great Barrier Reef, Australia. Paleoceanography, 22, PA2218, doi:10.1029/2006PA001377.

McGregor, S., A. Timmermann, and O. Timm, 2010: A unified proxy for ENSO variability since 1650 . Climate Past, 6, 1-17.

Min, S.-K., S. Legutke, A. Hense, and W.-T. Kwon, 2005: Internal variability in a 1000-yr control simulation with the coupled climate model ECHO-G - I. Near-surface temperature, precipitation and mean sea level pressure. Tellus, 57A, 605-621.

Neale, R. B., J. H. Richter, and M. Jochum, 2008: The impact of convection on ENSO: From a delayed oscillator to a series of events. J. Climate, 21, 5904-5924.

Okumura, Y. M., and C. Deser, 2010: Asymmetry in the duration of El Niño and La Niña. J. Climate, 23, 5826-5843.

Quinn, T. M., F. W. Taylor, and T. J. Crowley, 2006: Coral-based climate variability in the western Pacific warm pool since 1867. J. Geophys. Res., 111, C11006, doi:10.1029/2005JC003243.

Rayner, N. A., D. E. Parker, E. B. Horton, C. K. Folland, L. V. Alexander, D. P. Rowell, E. C. Kent, and A. Kaplan, 2003: Global analyses of sea surface temperature, sea ice, and night marine air temperature since the late nineteenth century. J. Geophys. Res., 108, 4407, doi:10.1029/2002JD002670.

Richter, J. H., and P. J. Rasch, 2008: Effects of convective momentum transport on the atmospheric circulation in the Community Atmosphere Model, version 3. J. Climate, 21, 1487-1499.

Roeckner, E., and Coauthors, 1996: The atmospheric general circulation model ECHAM-4: Model description and simulation of present-day climate. Max Planck Institute Rep. 218, 90 pp.

Schubert, S. D., M. J. Suarez, P. J. Pegion, R. D. Koster, and J. T. Bacmeister, 2004: Causes of long-term drought in the U.S. Great Plains. J. Climate, 17, 485-503.
Seager, R., and G. A. Vecchi, 2010: Greenhouse warming and the 21st century hydroclimate of southwestern North America. Proc. Natl. Acad. Sci. USA, 107, 21 277-21 282.

— , and N. Naik, 2012: A mechanisms-based approach to detecting recent anthropogenic hydroclimate change. J. Climate, 25, 236-261.

—, N. Harnik, Y. Kushnir, W. Robinson, and J. Miller, 2003: Mechanisms of hemispherically symmetric climate variability. J. Climate, 16, 2960-2978.

,-- W. A. Robinson, Y. Kushnir, M. F. Ting, H.-P. Huang, and J. Velez, 2005a: Mechanisms of ENSO-forcing of hemispherically symmetric precipitation variability. Quart. J. Roy. Meteor. Soc., 131, 1501-1527.

Y. Kushnir, C. Herweijer, N. Naik, and J. Velez, 2005b: Modeling of tropical forcing of persistent droughts and pluvials over western North America: 1856-2000. J. Climate, 18, 4068-4091.

Smith, T. M., R. W. Reynolds, T. C. Peterson, and J. Lawrimore, 2008: Improvements to NOAA's historical merged landocean surface temperature analysis (1880-2006). J. Climate, 21, 2283-2296.

Solomon, S., D. Qin, M. Manning, M. Marquis, K. Averyt, M. M. B. Tignor, H. L. Miller Jr., and Z. Chen, Eds., 2007: Climate Change 2007: The Physical Science Basis. Cambridge University Press, $996 \mathrm{pp}$.

Trenberth, K. E., G. W. Branstator, D. Karoly, A. Kumar, N.-C. Lau, and C. Ropelewski, 1998: Progress during TOGA in understanding and modeling global teleconnections associated with tropical sea surface temperatures. J. Geophys. Res., 103 (C7), 14 291-14 324

Tung, K.-K., and J. Zhou, 2010: The Pacific's response to surface heating in $130 \mathrm{yr}$ of SST: La Niña-like or El Niño-like? J. Atmos. Sci., 67, 2649-2657.

Vecchi, G. A., and B. J. Soden, 2007: Global warming and the weakening of the tropical circulation. J. Climate, 20, 43164340

- — - A. T. Wittenberg, I. M. Held, A. Leetmaa, and M. J. Harrison, 2006: Weakening of tropical Pacific atmospheric circulation due to anthropogenic forcing. Nature, 441, 73-76.

, A. C. Clement, and B. J. Soden, 2008: Examining the tropical Pacific's response to global warming. Eos, Trans. Amer. Geophys. Union, 89, doi:10.1029/2008EO090002.

Wara, M. W., A. C. Ravelo, and M. L. Delaney, 2005: Permanent El Niño-like conditions during the Pliocene warm period. Science, 309, 758-761.

Webster, P. J., 1981: Mechanisms determining the atmospheric response to large-scale sea surface temperature anomalies. J. Atmos. Sci., 38, 554-571.

Wittenberg, A. T., 2009: Are historical records sufficient to constrain ENSO simulations? Geophys. Res. Lett., 36, L12702, doi:10.1029/2009GL038710.

— A. Rosati, N.-C. Lau, and J. J. Ploshay, 2006: GFDL's CM2 global coupled climate models. Part III: Tropical Pacific climate and ENSO. J. Climate, 19, 698-722.

Yeh, S.-W., B. P. Kirtman, J.-S. Kug, W. Park, and M. Latif, 2011: Natural variability of the central Pacific El Niño event on multi-centennial time scales. Geophys. Res. Lett., 38, L02704, doi:10.1029/2010GL045886.

Zebiak, S. E., and M. A. Cane, 1987: A model El Niño-Southern Oscillation. Mon. Wea. Rev., 115, 2262-2278.

Zhang, W., J. Li, and X. Zhao, 2010: Sea surface temperature cooling mode in the Pacific cold tongue. J. Geophys. Res., 115, C12042, doi:10.1029/2010JC006501. 